\title{
Ceratocystis species, including two new taxa, from Eucalyptus trees in South Africa
}

\author{
Gilbert Kamgan Nkuekam $^{1 *}$, Michael J. Wingfield ${ }^{1}$, Jolanda Roux ${ }^{1}$ \\ ${ }^{1}$ Department of Microbiology and Plant Pathology, Forestry and Agricultural Biotechnology Institute \\ (FABI), University of Pretoria, Private Bag X20 Hatfield 0028, Republic of South Africa. \\ Corresponding author. Email: jolanda.roux@fabi.up.ac.za
}

\begin{abstract}
The ascomycete genus Ceratocystis (Microascales, Ceratocystidaceae) includes important fungal pathogens of trees, including Eucalyptus species. Ceratocystis species and their Thielaviopsis asexual states are typically associated with insects, such as nitidulid beetles, that spread them over long distances. Eucalyptus trees comprise a substantial component of the forestry industry in South Africa, however, limited information is available regarding Ceratocystis species that infect these trees. In this study, Ceratocystis species were collected from wounds on Eucalyptus trees in all the major plantation regions of South Africa, as well as from insects associated with these wounds. Both morphology and multigene DNA sequence analyses, using three nuclear loci, were used to identify the Ceratocystis species. Of the 260 isolates collected, nine Ceratocystis species, of which two were represented only by their Thielaviopsis anamorph states were identified. These species were C. eucalypticola, C. pirilliformis, $C$. savannae, C. oblonga, C. moniliformis, T. basicola, T. thielavioides and two Ceratocystis species that are described here as $C$. salinaria sp. nov. and $C$. decipiens sp. nov. Insects associated with these Ceratocystis species were Brachypeplus depressus (Nitidulidae), Carpophylus bisignatus, C. dimidiatus (Nitidulidae), Xyleborus affinis (Scolytidae), Litargus sp. (Mycetophagidae) and a Staphylinid (Staphylinidae) species.
\end{abstract}

Keywords Ascomycetes, Ceratocystidaceae, forestry, fungal tree pathogens, Microascales, Nitidulidae, Thielaviopsis, wounds. 


\section{Introduction}

Species in the fungal genus Ceratocystis Ellis \& Halsted (Ascomycetes: Microascales, Ceratocystidaceae), and their Thielaviopsis Went anamorphs, include important pathogens of agricultural and forestry crops (Kile 1993; Roux and Wingfield 2009). These fungi can cause diseases including stem cankers, root and fruit rot, as well as vascular wilts. The type species of Ceratocystis, C. fimbriata Ellis \& Halsted sensu stricto (s.s.), is the causal agent of sweet potato black rot disease (Halsted 1890; Halsted and Fairchild 1891). Other important diseases caused by Ceratocystis species include canker stain of plane trees caused by C. platani (Walter) Engelbrecht \& Harrington (Walter et al. 1952; Panconesi 1999), oak wilt caused by C. fagacearum (Bretz) J. Hunt (Juzwik et al. 2008; Sinclair and Lyon 2005) and wilt of Acacia mearnsii de Wild trees caused by C. albifundus De Beer, Wingfield \& Morris (Morris et al. 1993; Wingfield et al. 1996).

Ceratocystis species require wounds to infect their hosts (Moller and Devay 1968; Walter et al. 1952; Kile 1993) and are associated with insects that act as their vectors. Most Ceratocystis species are vectored by sap-feeding nitidulids and flies in what is considered a non-specific association (Cease and Juzwik 2001; Moller and Devay 1968). There is, however, growing evidence that the association between some nitidulid beetles and Ceratocystis species, such as C. fagacearum, are not entirely casual as was previously believed (Juzwik et al. 2004; Hayslett et al. 2007). Some Ceratocystis species, such as $C$. polonica (Siemaszko) C. Moreau, C. laricicola Redfern \& Minter, C. rufipenni Wingfield, Harrington \& Solheim and C. fujiensis M. J. Wingf., Yamaoka \& Marin, occur on conifers and are vectored by bark beetles in what is considered a specific association (Harrington and Wingfield 1998; Wingfield et al. 1997; Marin et al. 2005).

There have been increasing numbers of reports of Ceratocystis species infecting or causing diseases of Eucalyptus during the course of the last ten years (Roux and Wingfield 2009). Thirteen Ceratocystis species have been reported infecting wounds on non-native Eucalyptus trees in plantations worldwide. C. atrox M. Van Wyk \& M.J. Wingfield (VanWyk et al. 2007a), C. eucalypti Z.Q. Yuan \& Kile (Kile et al. 1996), C. corymbiicola Kamgan-Nkuek. \& Jol. Roux and C. tyalla Kamgan-Nkuek. \& Jol. Roux are known only from Australia (Kamgan Nkuekam et al. 2012), C. neglecta M. van Wyk, Jol. Roux \& C. Rodas, C. ecuadoriana M. Van Wyk \& M.J. Wingf. and C. curvata M. Van Wyk \& M.J. Wingf. from Colombia (Rodas et al. 2008; Van Wyk et al. 2011), C. fimbriatomima M. van Wyk \& M.J. Wingf. from Venezuela (Van Wyk et al. 2009), C. zombamontana R.N. Heath \& Jol. Roux from Malawi (Heath et al. 2009a), C. moniliformis (Hedgcock) Moreau from South Africa and Tanzania (Heath et al. 2009a), C. pirilliformis I. Barnes \& M.J. Wingf. from Australia and South Africa (Barnes et al. 2003a; Roux et al. 2004; Kamgan Nkuekam et al. 2009), C. eucalypticola M. van Wyk \& M.J. Wingf. from South Africa (Van Wyk et al. 2012) and C. fimbriata sensu lato (s.l.) from Brazil (Ferreira et al. 1999), 
Uganda (Roux et al. 2001), Uruguay (Barnes et al. 2003b), Thailand and Indonesia (Van Wyk et al. 2012). Of these, C. fimbriata s.l. has been shown to cause wilt and death of Eucalyptus trees in Brazil (Ferreira et al. 1999), Uganda (Roux et al. 2001) and Uruguay (Barnes et al. 2003b), while $C$. eucalypticola appears to be the cause of disease on Eucalyptus trees in the Republic of Congo (Roux et al. 1999).

Three Ceratocystis species have been reported from wounds on Eucalyptus trees in South Africa. These are C. eucalypticola, first reported as C. fimbriata s.l. (Roux et al. 2004), C. moniliformis and C. pirilliformis (Roux et al. 2004; Kamgan Nkuekam et al. 2009). C. eucalypticola and C. pirilliformis have not been associated with naturally dying Eucalyptus trees in South Africa, but artificial inoculation with these fungi in both the field and greenhouse resulted in distinct lesions, suggesting that they have the potential to kill these trees (Roux et al. 2004). Other Ceratocystis species known from trees in South Africa occur on non-native A. mearnsii (Morris et al. 1993; Wingfield et al. 1996) or indigenous trees (Roux et al. 2007; Kamgan Nkuekam et al. 2008). In this regard, there is growing concern that Ceratocystis species can shift hosts, such as is the case for C. albifundus, first isolated from native Protea species in South Africa (Gorter 1977) and later found causing disease on non-native A. mearnsii trees in plantations (Morris et al. 1993; Wingfield et al. 1996; Roux and Wingfield 2009).

Very little is known regarding the insect associates of Ceratocystis species in South Africa. In a recent study considering the epidemiology of the wattle wilt pathogen, $C$. albifundus, in the country, this fungus and Ceratocystis oblonga R.N. Heath \& Jol. Roux were isolated from three nitidulid (Coleoptera, Nitidulidae) beetle species namely, Brachypeplus depressus Erichson, Carpophilus bisignatus Boheman and Ca. hemipterus L. (Heath et al. 2009b). These insects were collected from both indigenous woodlands and from commercial plantations of non-native A. mearnsii trees, where they were either caught in insect traps or collected from beneath bark flaps on cut stumps (Heath et al. 2009b). The presence of these fungi on free-flying nitidulid beetles and on insects occurring on fungal mats growing under bark flaps suggested that nitidulid beetles are vectors of $C$. albifundus and C. oblonga on both native trees and A. mearnsii in its non-native range in South Africa (Heath et al. 2009b).

Previous studies of Ceratocystis species on Eucalyptus in South Africa have been limited to a small number of geographic and climatic areas and a limited numbers of Eucalyptus species. The recent discoveries of previously undescribed Ceratocystis species from native trees in South Africa, as well as from numerous Eucalyptus spp. in Australia and South America, suggest that additional species could occur on Eucalyptus trees in South Africa. This, together with the limited information regarding the biology and epidemiology of Ceratocystis species on Eucalyptus prompted this study aimed at expanding the base of knowledge of the diversity of Ceratocystis species infecting these trees in the country. The nitidulid vectors of these fungi in commercial Eucalyptus plantations were also identified. 


\section{Materials and methods}

\section{Collection of fungal isolates}

Ceratocystis species were collected from wounds on Eucalyptus trees in South African plantations over a two year period from February 2007 to December 2008. Collection sites covered the majority of the Eucalyptus growing areas of the country and included localities near Louis Trichardt and Tzaneen (Limpopo Province), Lothair and Sabie (Mpumalanga Province), George, Cape Town and Stellenbosch (Western Cape Province), Kumbo and Lotobeni (Eastern Cape Province) and localities near KwaMbonambi and Pietermaritzburg (KwaZulu-Natal Province). Samples were mainly collected from the stumps of freshly harvested trees and from logs, either on the plantation floor or at the harbor.

Pieces of bark or wood were collected from cut stumps and transported to the laboratory as described by Kamgan Nkuekam et al. (2009). Isolation and purification of fungi from samples followed the protocol described by Kamgan Nkuekam et al. (2009). Isolates were deposited in the culture collection (CMW) of the Forestry and Agricultural Biotechnology Institute (FABI), University of Pretoria, South Africa. Representative specimens have also been deposited with the Centraalbureau voor Schimmelcultures (CBS), Utrecht, Netherlands. Dried specimens of representative isolates were deposited in the National Collection of Fungi (PREM), Pretoria, South Africa.

\section{Collection of insects}

Insects were collected from beneath bark flaps on cut stumps of Eucalyptus trees. This was done using an aspirator (Fergusson 1982). Insects were stored in separate Eppendorf tubes and transported to the laboratory following the method described by Kamgan Nkuekam et al. (2012). The insects were grouped based on morphological characteristics and viewed using an Axiocam dissection microscope (Carl Zeiss Ltd., Germany). Representatives of each insect group were preserved in $70 \%$ ethanol prior to identification by Dr. Andrew Cline, Senior Insect Biosystematist, Plant Pest Diagnostics Center, California Department of Food and Agriculture, United States of America.

Isolation of fungi from insects was done using carrot baiting (Moller and Devay 1968, Heath et al. 2009b). Mycelial strands, ascomata or ascospores of putative Ceratocystis species were then transferred from the carrot surfaces to $2 \%$ malt extract agar (MEA: $20 \mathrm{gl}^{-1}$ malt extract and $15 \mathrm{gl}^{-1}$ agar, Biolab,

Midrand, South Africa and $1000 \mathrm{ml}$ sterile deionised water) containing $0.05 \mathrm{gl}^{-1}$ of the antibiotic streptomycin sulphate (SIGMA-ALDRICH, Steinheim, Germany).

\section{Morphological characterization}

Ceratocystis isolates were incubated at $25^{\circ} \mathrm{C}$ until sporulation and then grouped based on colour (Rayner 1970) and macro-morphology on MEA. Morphological structures including ascomata and ascospores, 
phialides and conidia from isolates representing each morphotype were mounted in $80 \%$ lactic acid on glass microscope slides and examined using a Zeiss Axiocam light microscope (München-Hallbergmoos, Germany). Fifty measurements of all characteristic morphological features were made for isolates chosen to represent the types of new species and ten measurements were made for additional isolates. Measurements were computed as (minimum -) mean minus st. dev. - mean plus st. dev. (- maximum).

Scanning Electron Microscopy (SEM) was used to examine spores and the asexual states of the Ceratocystis species. Specimens were prepared for SEM as described by Grobbelaar et al. (2009). The specimens were critical point dried (Bio-Rad E3000, Watford, England), then mounted and coated with gold in a sputter coater (Emitech K550X, Ashford, England) and examined using a JEOL JSM-840 scanning electron microscope (JEOL, Tokyo, Japan).

\section{Growth in culture}

Growth in culture was examined for two isolates of each new species identified in this study. A disk of agar $(9 \mathrm{~mm}$ diam.) bearing mycelium of the test isolates was transferred from the actively growing margins of seven-day-old cultures and placed with the mycelial surface facing downwards, at the centres of $90 \mathrm{~mm}$ Petri dishes containing 2\% MEA. The plates were incubated in the dark for 10 days at temperatures ranging from 5 to $35^{\circ} \mathrm{C}$ at 5 degree intervals. Five replicate plates were used for each isolate at each temperature considered. Two diameter measurements, perpendicular to each other, were taken daily for each colony and the averages of ten diameter measurements for each temperature were computed.

\section{DNA sequence comparisons}

Single spore drops collected from the apices of ascomata in pure cultures were transferred to $2 \%$ MEA and allowed to grow for 7-10 days. Mycelium was scraped from the surfaces of the actively growing cultures and transferred to $1.5 \mathrm{ml}$ Eppendorf tubes using a sterile hypodermic needle. DNA was extracted from all isolates using PrepMan Ultra Sample Preparation Reagent (Applied Biosystems, California, USA) following the manufacturer's instructions.

The internal transcribed spacer regions (ITS1, ITS2) and 5.8S gene of the ribosomal RNA operon were amplified on an Eppendorf Mastercycler (Merck, Germany) using primers ITS1 and ITS4 (White et al. 1990). Part of the $\beta$-tubulin gene (BT1) and the transcription elongation factor- $1 \alpha$ gene (TEF) were also amplified using the primers $\beta \mathrm{t} 1 \mathrm{a}$ and $\beta \mathrm{t} 1 \mathrm{~b}$ (Glass and Donaldson 1995), EF1F and EF2R (Jacobs et al. 2004) respectively.

Due to the poor resolution in species delineation recently observed for the $C$. pirilliformis clade of Ceratocystis, two additional gene regions were tested on species in this clade, to determine whether they could be used to better define taxa in this group. These gene regions comprised of a portion of the RNA 
polymerase II subunit (RPB2) recommended by the AFTOL database, using the primers fRPB2-5F (5'GAYGAYMGWGATCAYTTYGG-3') and RPB2-6R (5'-GCAGGRCARACCAWMCCCCA-3') (www. AFTOL.org), and the BT2 gene regions of the $\beta$-tubulin gene using the primers $\beta \mathrm{t} 2 \mathrm{~A}$ and $\beta \mathrm{t} 2 \mathrm{~B}$ (Glass and Donaldson 1995).

The PCR reaction mixtures, as well as the thermal cycling conditions, were the same as those described previously (Kamgan Nkuekam et al. 2008). A $5 \mu$ l aliquot of the PCR products was pre-stained with GelRed $^{\mathrm{TM}}$ Nucleic Acid Gel stain (Biotium, Hayward, USA) and separated on a 1\% agarose gel and visualized under UV light. PCR products were purified using Sephadex G-50 Gel (Sigma-Aldrich), following the manufacturer's instructions. The concentrations of the purified PCR products were determined using a Nanodrop ND-1000 Spectrophotometer (Nanodrop Technologies, Rockland, USA). Sequencing reactions were performed using the Big Dye cycle sequencing kit with Amplitaq DNA polymerase, FS (Perkin-Elmer, Warrington, UK) following the manufacturer's protocol on an ABI PRISM 3100 Genetic Analyzer (Applied Biosystems). Sequencing PCR was prepared as described by Kamgan Nkuekam et al. (2008) and both DNA strands were sequenced.

A preliminary identity for the isolates was obtained by performing a similarity search (standard nucleotide BLAST) against the GenBank database (http://www.ncbi.nlm.nih.gov). Sequences of both DNA strands for each isolate were examined visually and combined using the programme Sequence Navigator v. 1.01 (ABI PRISM, Perkin Elmer). Additional sequences of the ex-type species of related Ceratocystis species and Thielaviopsis species were obtained from the GenBank database (http://www.ncbi.nlm.nih.gov) for comparisons. Sequences were aligned using the E-INS-i option in the online version of MAFFT 6 (Katoh and Toh 2008).

\section{Phylogenetic analyses}

Phylogenetic analyses of sequences for each group of isolates separated based on morphology were performed independently of each other. Phylogenetic analyses of data sets for each of the three nuclear loci (ITS, BT1, TEF) were performed both separately and as combined data sets. For each data set, maximum parsimony (MP), Bayesian analyses (MB), and maximum likelihood (ML) analyses were done.

MP analyses were performed in PAUP 4.0b10 (Swofford 1998), using the following settings: 100 random sequence addition replicates, tree bisection-recognition (TBR) branch swapping, and 'multrees' option in effect. Confidence levels of the MP phylogenies were estimated with the bootstrap method (1000 replications). The same parameters were used for the RPB2 and BT2 gene regions in the analyses of the C. pirilliformis clade.

Bayesian analyses based on Markov chain Monte Carlo (MCMC) were performed with MrBayes 3.1.2 (Huelsenbeck and Ronquist 2001) as outlined previously (Kamgan Nkuekam et al. 2012). Appropriate substitution models were determined using the Akaike Information Criterion (AIC) in 
MrModeltest 2.2 (http://www.abc.se/ nylander/). The best fit model of evolution applied to ITS, BT1 and TEF are summarized in Table 1. Burn-in values were determined using Tracer 1.4 (http://beast.bio.ed.ac.uk/Tracer) to discard trees that formed before the point of convergence, and the posterior probability in the majority rule consensus trees were calculated by MCMC sampling in MrBayes V3.1.2, using the best-fit model of evolution (Table 1).

Maximum likelihood (ML) analyses were conducted online using PhyML 3.0 (Guindon and Gascuel 2003). The AIC was used in ModelTest 3.7 (Posada and Crandall 1998) to select appropriate substitution models for the three data sets (Table 1).

The level of polymorphism in sequence variation between closest related species was analyzed with the genetic software programme MEGA V4 (Molecular Evolutionary Genetics Analysis) (Tamura et al. 2007). Sequences for each gene region considered were examined to determine the number of fixed base pair differences that separate closest related taxa. Allele networks were constructed with the programme TCS (Clement et al. 2000) to illustrate the relationship between isolates of closely related species.

\section{Pathogenicity tests}

The pathogenicity of two new Ceratocystis species identified in this study was tested in a quarantine greenhouse. Two strains of each species were used to inoculate ten, approximately two-year-old $(\sim 1 \mathrm{~cm}$ diameter), Eucalyptus grandis (clone TAG5) trees. Two additional trees of the same age were inoculated with a sterile agar disc to serve as controls. The experimental design and conditions for inoculation were the same as those described by Kamgan Nkuekam et al. (2008). Six weeks (42 days) after inoculation, the lengths of lesions on the bark surface and in the xylem of each tree were measured. Re-isolations were made from the lesions to meet the requirements of Koch's postulates. All lesion length data were analyzed using the GLM procedure in SAS/STAT (SAS Institute Inc. 1999).

\section{Results}

\section{Collection of fungal isolates}

A total of one hundred Ceratocystis isolates were obtained from wounds on Eucalyptus trees sampled. More than 300 trees were sampled in the process and isolates were obtained from all the areas sampled. These spanned six different Provinces and a wide variety of climatic conditions (Table 2). Eucalyptus species from which Ceratocystis isolates were obtained included six different species, namely E. grandis W. Hill: Maiden, E. nitens H.Deane \& Maiden, E. saligna Sm., E. maculata Hook., E. cloeziana F. Muell and E. diversicolor F. Muell (Table 2). 


\section{Fungal isolates from insects}

A wide variety of insects were found in four of the six Provinces sampled. More than 385 insects, spanning five genera in three different families were collected. Members of the Nitidulidae were the most common insects found, accounting for 255 specimens collected. These nitidulids were identified as Brachypeplus depressus Erichson (120 specimens), Carpophilus bisignatus Boheman (20 specimens) and C. dimidiatus Fabricius (25 specimens). Ninety other nitidulid beetles were of a Carpophilus sp. that could not be identified to species level. Other insects collected resided in the Staphylinidae (100 specimens), Lithargus sp. (Coleoptera: Mycetophagidae) (10 specimens) and Xyleborus affinis (Coleoptera: Scolytidae) (20 specimens) (Table 3). A total of 162 isolates of Ceratocystis were obtained from the insects collected in this study (Table 3).

\section{Morphological characterization}

Based on colony colour and the morphology of the ascomata, ascospores, conidiogenous cells and conidia produced on MEA, three main morphological groups in the genus Ceratocystis were identified. The first set of isolates produced colonies and structures typical of species in the C. fimbriata (s.l.) complex and these are referred to as the $C$. fimbriata group. These isolates could be further subdivided into two sub-groups. One of these sub-groups resembled those of $C$. fimbriata s.s., the other was typical of those of $C$. pirilliformis as described by Barnes et al. (2003a). The second set of isolates produced colonies with morphologies typical to those in the C. moniliformis s.l. complex and were treated as such. The third set of isolates produced colonies having only an asexual Thielaviopsis state of Ceratocystis.

\section{DNA sequence comparisons and phylogenetic analyses}

The ITS gene region for all isolates in the C. fimbriata s.l. group generated contigs of $\sim 600 \mathrm{bp}$. For the BT1 and TEF gene regions, only a few representative isolates were selected for DNA sequencing. Amplification generated contigs of $\sim 550$ and $\sim 900$ bps for the BT1 and TEF, respectively. A preliminary nucleotide Blast against the GenBank database using data sets from each of the three main gene regions revealed that some of the isolates were similar to either C. fimbriata s.s., C. manginecans M. van Wyk, Al Adawi \& M.J. Wingf. or C. eucalypticola and the others were closely related to C. pirilliformis.

Comparison of the ITS, BT1 and TEF sequence data of selected isolates in the C. fimbriata s.l. group with those of related Ceratocystis species from GenBank (Table 4) showed that one group of isolates represented C. eucalypticola and the other C. pirilliformis (Fig. 1). These results were confirmed using maximum parsimony, Bayesian and maximum likelihood analyses (ML). Tree statistics for maximum parsimony analysis are summarized in Table 5. Comparison of sequence data for all three gene regions confirmed the identities of the isolates as either C. pirilliformis or C. eucalypticola (Fig. 2). These 
isolates had identical BT1 sequences and the TEF sequences differed only in a small number of bases in multiple base repeat regions (data not shown).

Isolates identified as $C$. pirilliformis fell within a clade comprising $C$. zombamontana, $C$. obpyriformis and $C$. polyconidia. The resolution between the four species was poor, especially between C. pirilliformis and C. zombamontana. For example, there were seven base pair differences between the ex-type strain of $C$. pirilliformis and the ex-type strain of $C$. zombamontana (Table 6, 7). These differences resided mainly in the T-rich multiple repeat regions of the ITS gene and were not informative in the analyses (Fig. 1). Some isolates identified as C. pirilliformis had ITS sequences the same as those for the ex-type strain of $C$. zombamontana (Table 6,7). An unrooted tree showing relationships between the ex-type strain of $C$. pirilliformis and its closest phylogenetic neighbors was also constructed, based on three gene regions (ITS, BT1, TEF) (Fig. 3) and this showed that strains of C. zombamontana were identical to those of $C$. pirilliformis.

Polymerase chain reactions using RPB2 primers were unspecific resulting in multiple DNA fragments when resolved on agarose gels. DNA fragments of expected size were extracted from the gel and sequenced directly using the same primers used for PCR amplification. Sequence data obtained were used for phylogenetic analyses using maximum parsimony. Based on this analysis, C. pirilliformis, $C$. zombamontana and C. obpyriformis formed a single monophyletic clade with $100 \%$ homology supported by a bootstrap of $100 \%$ (data not shown). However, C. polyconidia fell within a single well resolved and highly supported clade and was the only species that could be separated from other taxa using this marker.

BT2 primers used in polymerase chain reactions were specific resulting in single DNA fragments when resolved on agarose gels. However, in phylogenetic analyses using maximum parsimony in PAUP, all known species in $C$. pirilliformis s.l. resided in a single and highly supported clade with $100 \%$ homology (data not shown).

Seven haplotypes were identified within the $C$. pirilliformis s.l. clade in multilocus analysis using TCS (Table 8, Fig. 4). These comprised C. obpyriformis (CMW23807, CMW23808) and C. polyconidia (CMW23809, CMW23818), which each formed a single haplotype. The ex-type strain of C. pirilliformis (CMW6569) and its paratype strain (CMW6579) fell within two different haplotypes (Fig. 4). C. zombamontana strains were intermingled with isolates sequenced in this study and these were closely related to $C$. pirilliformis. The seven haplotypes resulting from the analysis were interconnected and formed a single allelic network.

Isolates resembling those in the $C$. moniliformis complex could be distinguished only based on sequence data for the BT1 (Fig. 5) and TEF (Fig. 6) gene regions, with no resolution obtained for the ITS gene region (data not shown). This is similar to previous reports for the C. moniliformis s.l. complex (Van Wyk et al. 2006a; Kamgan Nkuekam et al. 2008). Sequence data for the BT1 gene region grouped 
isolates into five clades (Fig. 5, Table 4) that represented C. savannae, C. moniliformis, C. oblonga and two unidentified species. The identities were supported by Bayesian, MP and ML analyses. Isolates representing C. moniliformis were 100\% identical to those of the type species. Minor differences of up to two base pairs were found between some isolates identified as $C$. savannae and the ex-type isolate of the fungus (Table 9, 10). Some isolates in the larger C. oblonga clade differed from the ex-type isolate in up to three base pairs (Table 9, 10). Unrooted trees illustrating relationships between the two unidentified species and their closest phylogenetic neighbors showed that they represented two undescribed taxa (Fig. 7).

Analyses of the TEF data set for the C. moniliformis s.l. isolates were not concordant with those for the BT1 data set, but also revealed five different clades (Fig. 6, Table 4). These clades represented $C$. savannae and C. oblonga, which could not be differentiated from each other using TEF sequence data, $C$. moniliformis and three separate clades including isolates from Eucalyptus and insects. All clades were supported by Bayesian, MP and ML analyses (Fig. 6, Table 4). There were three base pair differences between Eucalyptus isolates identified as C. moniliformis and the ex-type isolate of the species. Minor variations were found among isolates identified as $C$. savannae and the ex-type isolate of the species. Isolates residing in Clade 1 of the C. moniliformis s.l. group, identified as representing an undescribed taxon based on the BT1 gene region split into two well-supported clades in the TEF analyses, different from other Ceratocystis reference strains (Fig. 6). A total of 11 bp differences (10 indels and 1 fixed bp) separated the two clades (Table 10). Isolates residing in Clade 2 formed a single well resolved and strongly supported clade in the TEF tree, similar to the results for the BT1 data set (Fig. 5, 6). Analyses of a TEF data set including only $C$. savannae, C. oblonga and their closest relatives and visualization of results in an unrooted tree confirmed the unique nature of Clade 2 isolates (Fig. 7, 8). Isolates of $C$. savannae and C. oblonga could not be distinguished from each other based on the TEF gene region (Fig. 6). For the TEF data set, all analyses, including Bayesian, MP as well as ML were concordant.

Parsimony analysis of the combined dataset for the ITS, BT1 and TEF gene regions for isolates in the C. moniliformis s.l. group, and including related Ceratocystis species from GenBank (Table 4) resolved the isolates into five different clades (Fig. 9, Table 4). Sequence discordance found in TEF data sets remained present except that the unidentified species that split in two clades in the TEF tree, resided in a larger well-supported clade showing considerable sequence variation among isolates within the clade (Fig. 9). These data were confirmed by the $50 \%$ majority rule tree obtained from Bayesian analyses, a bootstrap tree obtained from MP as well as from ML analyses.

Isolates residing in the group of isolates where only a Thielaviopsis state was present were considered only based on sequence data for the ITS gene region. This region generated a contig of $\sim 500$ bp. A preliminary nucleotide Blast against the GenBank database confirmed that isolates reside in Thielaviopsis. Comparison of the ITS data set for these isolates with sequences for other Thielaviopsis 
species in GenBank, using parsimony analysis, resulted in a phylogenetic tree where one set of the isolates grouped with T. basicola (Berk. Et Br.) Ferr (AF275490, AF275494), and the second set of isolates grouped with T. thielavioides (Peyr.) A.E. Paulin, T.C. Harr. \& McNew (AF275487, AF275488) strains with 100\% bootstrap support at the nodes (Fig. 10).

\section{Taxonomy}

Based on phylogenetic analyses of sequence data for three gene regions, two previously unknown Ceratocystis species are recognized from Eucalyptus or insects associated with these trees in South Africa. These two fungi reside in the larger C. moniliformis s.l. complex, and were clearly separated based on sequence data for reference strains of other species in this group. Descriptions are provided for them in the following section. Furthermore, C. zombamontana and C. pirilliformis could not be separated based on DNA sequence data or morphology. C. zombamontana is consequently reduced to synonymy with C. pirilliformis.

Ceratocystis salinaria Kamgan-Nkuek. \& Jol. Roux sp. nov. (Fig. 11) MB519695

Etymology: Salinaria "pertaining to salt-works" used by Vitruvius ( $1^{\text {st }}$ Century AD) and reflects the fact that the fungus was found in the Soutpansberg area, South Africa, famous for its salt pans.

Colonies Buff (19',d) coloured, ascomata produced rapidly and abundantly, scattered over the colonies and embedded within aerial mycelium, giving colonies a Honey (19'’b) coloured appearance. Aerial mycelium distributed evenly across the colonies giving cultures a fluffy appearance. Reverse of colonies Honey (19' 'b). Colony diameter reaching $45.5 \mathrm{~mm}$ in 3 days on MEA at $25^{\circ} \mathrm{C}$. Optimal growth at $25^{\circ} \mathrm{C}$, growth at $30^{\circ} \mathrm{C}$ with colony diameter reaching $43 \mathrm{~mm}$ in 3 days. No growth at $5^{\circ} \mathrm{C}$ or $37^{\circ} \mathrm{C}$. Mycelium forming thick mat on agar. Hyphae smooth, not constricted at septa. Ascomata scattered over the colonies. Ascomatal bases dark brown, globose to obpyriform, (138.0-) 189.0-247.5 (-272.0) $\mu \mathrm{m}$ long and (124.0-) 155.5-204.5 (-232.5) $\mu \mathrm{m}$ wide, with dark conical spines (5.0-) 6.5-9.0 (-11.0) $\mu \mathrm{m}$ and hyphal hair. Ascomatal necks dark brown, (297.5-) 379.5-499.5 (-592.0) $\mu \mathrm{m}$ long, middle of necks (19.0-) 23.5$28.5(-31.5) \mu \mathrm{m}$ wide, tips of necks (11.5-) 12.0-16.5 (-23.0) $\mu \mathrm{m}$ wide, producing sticky and hyaline spore drops at the tips of divergent ostiolar hyphae, (19.5-) 24.5-100.5 (-123.5) $\mu \mathrm{m}$ long and with disclike (disciform) bases, (43.0-) 55.0-73.5 (-88.0) $\mu \mathrm{m}$ wide at bases. Asci not seen, evanescent, deliquescing early in the development. Ascospores hat-shaped, hyaline, aseptate, invested in sheaths (4.5-) 5.0-5.5 (6.0) x (2.5-) 3.0-3.5 (-4.0) $\mu \mathrm{m}$, accumulating in round, straw yellow (21'd) spore drops, becoming creamy with age.

Anamorph: Thielaviopsis. Conidiophores singly on mycelium, phialidic, hyaline, tubular (18.5-) 20.5-28.5 (-39.5) x (2.0-) 2.5-3.0 (-3.5) $\mu \mathrm{m}$, colarettes absent. Conidia hyaline, aseptate, two types, 
oblong (5.0-) 5.5-7.5 (-9.0) x (1.5-) 2.0-3.0 (-3.5) $\mu \mathrm{m}$ and bacilliform-shaped with rounded bases (6.5-) 7.5-9.5 (-10.5) x (1.0-) 1.5-2.5 (-3.0) $\mu \mathrm{m}$. Chlamydospores (aleuroconidia) not observed.

Specimen examined: South Africa, Limpopo Province, Soutpansberg area (S23 02,350', E030 14,209'), isolated from stumps of Eucalyptus maculata, 18/06/2007, G. Kamgan Nkuekam and J. Roux, holotype PREM 60557, living culture CMW25911 = CBS129733.

Additional specimens: South Africa, Limpopo Province, Soutpansberg area, from stumps of Eucalyptus saligna, 17/12/2008, G. Kamgan Nkuekam and J. Roux, paratype, living culture CMW30702=PREM 60558, from stumps of Eucalyptus saligna, 17/12/2008, G. Kamgan Nkuekam and J. Roux, paratype, living culture CMW30703 = PREM60559= CBS129734.

Ceratocystis decipiens Kamgan-Nkuek. \& Jol. Roux sp. nov. (Fig. 12) MB519696

Etymology: Decipiens, the Latin word for "deceiving" and referring to the fact that the fungus would be seen as a single species based on BT or two species based on TEF sequence data.

Colonies Buff (19',d) coloured, ascomata often absent or produced late in small quantities, scattered over the colonies. Reverse of colonies Honey (19'’b) from the edge, turning nearly Isabelline (17' 'i) towards the center. Colony diameters reaching $39 \mathrm{~mm}$ in 3 days on MEA at $30^{\circ} \mathrm{C}$. Optimal growth at $30^{\circ} \mathrm{C}$, no growth at $35^{\circ} \mathrm{C}$ or at $5^{\circ} \mathrm{C}$. Mycelium forming thick mat on agar, becoming fluffy towards the center. Hyphae septate, not constricted at septa. Ascomata scattered over the surface of the colonies or embedded in mycelium. Ascomatal bases dark brown, globose to obpyriform, (132.5-) 167.5-216.5 (258.5) $\mu \mathrm{m}$ long and (108.5-) 162.5-218.0 (-244.0) $\mu \mathrm{m}$ wide, with dark conical spines, (5.0-) 5.5-11.5 (16.5) $\mu \mathrm{m}$ and hyphal hair ornamentations. Ascomatal necks dark brown, (355.0-) 401.0-500.5 (-596.5) $\mu \mathrm{m}$ long, middle of necks (17.5-) 21.0-25.5 (-27.5) $\mu \mathrm{m}$ wide, tips of necks (9.5-) 11.0-13.0 (-16.0) $\mu \mathrm{m}$ wide, producing sticky, hyaline spore drops at the tips of divergent ostiolar hyphae, (13.0-) 15.5-24.5 (35.5) $\mu \mathrm{m}$ long and with disc-like (disciform) bases, (47.0-) 58.5-86.5 (-102.5) $\mu \mathrm{m}$ wide at bases. Asci not seen, evanescent, deliquescing early in the development. Ascospores hat-shaped, hyaline, aseptate, invested in sheaths (4.0-) 4.5-5.0 (-5.5) x (2.0-) 2.5-3.0 (-3.5) $\mu \mathrm{m}$, accumulating in round, straw yellow (21'd) spore drops, becoming creamy with age.

Anamorph: Thielaviopsis. Conidiophores singly on mycelium, phialidic, hyaline, tubular (15.5-) 21.5-30.5 (-35.0) x (2.0-) 2.5-3.5 (-4.0) $\mu \mathrm{m}$, colarettes absent. Conidia hyaline, aseptate, two types, oblong (4.5-) 5.5-6.5 (-7.5) x (1.5-) 2.0-2.5 (-3.5) $\mu \mathrm{m}$ and bacilliform-shaped (5.0-) 5.5-7.5 (-10.5) x (1.0) 1.5-2.0 (-2.5) $\mu \mathrm{m}$. Chlamydospores (aleuroconidia) not observed.

Specimen examined: South Africa, Limpopo Province, Soutpansberg area (S23 ${ }^{\circ}$ 02,350', 
E030 $\left.{ }^{\circ} 14,209^{\prime}\right)$, isolated from Staphilinid sp. obtained from stumps of a Eucalyptus saligna tree, 17/12/2008, G. Kamgan Nkuekam and J. Roux, holotype PREM60560, living culture CMW30855 = CBS129736.

Additional specimens: South Africa, Limpopo Province, Soutpansberg area, from wound on Eucalyptus cloeziana, 21/06/2007, G. Kamgan Nkuekam and J. Roux, paratype, living culture CMW25918=PREM60561 = CBS129735, from wound on Eucalyptus maculata, 21/06/2007, G. Kamgan Nkuekam and J. Roux, paratype, living culture CMW25914=PREM60562 = CBS129737.

Ceratocystis pirilliformis I. Barnes \& M.J. Wingfield, Mycologia 95:867. 2003

= Ceratocystis zombamontana R.N Heath \& Jol. Roux, Fungal Diversity 34:53. 2009.

C. zombamontana, described from Eucalyptus trees in Malawi (Heath et al. 2009a) was found to be phylogenetically indistinguishable from $C$. pirilliformis based on DNA sequence data for five gene regions. Strains of the two species have identical BT1, BT2, TEF and RPB2 sequences. Strains of $C$. zombamontana, including the ex-type strain, have identical ITS1, ITS2 and 5.8S sequences as strains of C. pirilliformis collected in the current study. A number of morphological differences were previously reported for the two species. These included the fact that chlamydospores were produced in culture by $C$. pirilliformis and not by C. zombamontana, and the fact that C. zombamontana produced flask-shaped primary phialides compared to the cylindrical to lageniform phialides of $C$. pirilliformis (Heath et al. 2009a). A re-evaluation of isolates of $C$. zombamontana collected by Heath et al. (2009a) revealed the presence of chlamydospores in culture CMW15235 (Fig. 13). The measurements of chlamydospores in culture CMW15235 and those of the ex-type species of $C$. pirilliformis described by Barnes et al. (2003a) were found to overlap. Other than reducing C. zombamontana to synonymy with $C$. pirilliformis, the description of $C$. pirilliformis should include the fact that some strains of the fungus might often not produce chlamydospores in culture. In addition $C$. pirilliformis produces two types of phialides, a flaskshaped primary phialides and cylindrical to lageniform phialides.

This study reports nine Ceratocystis species, collected from six Provinces spanning various climatic conditions in South Africa. These include two species for which only the Thielaviopsis states were obtained. C. eucalypticola is the most widely spread species, occurring in four of the sampled Provinces (Fig. 14, Tables 2, 3). It was obtained from E. grandis trees and from a wide variety of insects (Table 2, 3). This is followed by $C$. pirilliformis obtained from three Provinces on four Eucalyptus species (E. cloeziana, E. diversicolor, E. grandis, E. saligna) and from B. depressus (Table 2, 3). C. oblonga was found in two Provinces (Limpopo and Mpumalanga) on E. grandis trees. It was also obtained from B. depressus, C. bisignatus and C. dimidiatus (Table 3). C. moniliformis was found in both Limpopo and Mpumalanga Provinces on two Eucalyptus species (E. grandis, E. maculata) and from a 
Staphilinid species (Table 2, 3). C. salinaria was found in two Provinces (Limpopo, Western Cape) on three Eucalyptus species (E. cloeziana, E. maculata, E. saligna), while C. decipiens was found exclusively in the Limpopo Province on two Eucalyptus species (E. cloeziana, E. maculata) and on a Staphilinid species (Table 2, 3). C. savannae was found in Limpopo Province, on two Eucalyptus species (E. cloeziana, E. maculata) and on B. depressus, C. bisignatus, C. dimidiatus and a Staphilinid species (Table 2, 3). T. basicola and T. thielavioides were obtained from nitidulid beetles collected in the Eastern Cape and KwaZulu-Natal Provinces respectively.

\section{Pathogenicity test}

Six weeks after inoculation, Eucalyptus trees were assessed for lesion development in the bark and cambium. Ceratocystis salinaria and $C$. decipiens produced very small lesions on both the bark and in the cambium of the E. grandis trees inoculated. On the bark, the mean lesion lengths (Lsmean) produced by C. salinaria and $C$. decipiens were $1.2 \mathrm{~cm}(\mathrm{R}=0.75, \mathrm{CV}=9.9, \mathrm{P}<0.0001$, Confidence limit $=95 \%)$ and $0.8 \mathrm{~cm}(\mathrm{R}=0.75, \mathrm{CV}=9.9, \mathrm{P}<0.0001$, Confidence limit $=95 \%)$, respectively, while on the cambium, the Lsmeans were $1.5 \mathrm{~cm}(\mathrm{R}=0.8, \mathrm{CV}=8.9, \mathrm{P}<0.0001$, Confidence limit $=95 \%)$ and $1 \mathrm{~cm}(\mathrm{R}=0.8, \mathrm{CV}=$ 8.9, $\mathrm{P}<0.0001$, Confidence limit $=95 \%$ ), respectively (data not shown). Lesions were present on both the bark (Lsmean $=1 \mathrm{~cm}, \mathrm{R}=0.75, \mathrm{CV}=9.9, \mathrm{P}<0.0001$, Confidence limit $=95 \%$ ) and the cambium $($ Lsmean $=1 \mathrm{~cm}, \mathrm{R}=0.8, \mathrm{CV}=8.9, \mathrm{P}<0.0001$, Confidence limit $=95 \%)$ of the control trees inoculated for the $C$. salinaria treatment while there were no lesions on either the bark or the cambium of the control trees inoculated for the $C$. decipiens treatment (data not shown). At the time of assessment, trees showed no signs of disease and neither $C$. salinaria nor $C$. decipiens could be re-isolated from the small lesions associated with their inoculation.

\section{Discussion}

Nine Ceratocystis species were identified in this study from Eucalyptus species and insects associated with them, in six Provinces of South Africa. Two of these, C. eucalypticola and C. pirilliformis reside in the C. fimbriata s.l. complex. Five of the other Ceratocystis species identified are members of the $C$. moniliformis s.l. complex and the remaining two were found only in the Thielaviopsis anamorph state. Species in the C. moniliformis s.l. clade included C. savannae, C. oblonga, C. moniliformis and two new taxa for which the names $C$. salinaria and $C$. decipiens were provided. The asexual species included $T$. basicola and $T$. thielavioides. In pathogenicity tests, C. salinaria and C. decipiens resulted in only small lesions on both the bark and the xylem of young Eucalyptus trees and they are, therefore, not considered pathogens of Eucalyptus trees in South Africa. 
Separation of Ceratocystis species based on morphology and phylogenetic inference from DNA sequence data is becoming increasingly difficult as new species are described. During the course of the past ten years, sequence data for the ITS, TEF and BT1 gene regions have been used to distinguish morphologically similar species in the C. fimbriata and C. moniliformis complexes from each other (Van Wyk et al. 2006a, 2007a, b; Kamgan Nkuekam et al. 2008). In this regard, the ITS gene region has provided most information for species in the C. fimbriata s.l. clade and the TEF and BT1 regions are most informative for species in the C. moniliformis s.l. complex (Van Wyk et al. 2006a, 2012; Kamgan Nkuekam et al. 2008). In this study, we used both separate analyses for different gene regions as well as combined analyses to infer the phylogenies of members of the C. moniliformis s.l. and C. fimbriata s.l. complex. This made it possible to avoid errors in interpretation that could arise from using either separate analyses or combined analyses exclusively, as suggested by Huelsenbeck et al. (1996).

Delimiting species in the C. moniliformis s.l. complex is especially problematic. This is not only due to lack of concordance between gene regions (Van Wyk et al. 2006a; Kamgan Nkuekam et al. 2008), but could also be due to the presence of pseudogenes that are often present in more than one copy (Podlaha and Zhang 2010; Rouchka and Cha 2009). In this study, isolates of C. decipiens formed a single clade based on BT1 sequences, but two distinct clades based on TEF sequences and they were identical based on ITS sequences. Because of these inconsistencies we have adopted a conservative approach where these isolates have been described as representing a single species. Similarly, isolates identified as representing C. oblonga were identical to the ex-type and other isolates of $C$. savannae based on TEF and ITS sequences, but differed from this species based on BT1 sequences. Differences were also found amongst $C$. oblonga isolates collected in this study and those representing the ex-type isolate of the species both in the TEF and BT1 gene regions, suggesting that they represent closely related but distinct taxa. We have, however, refrained from describing them as distinct as more robust markers should be used to support this decision.

The two new Ceratocystis species described in this study, C. salinaria and C. decipiens, are members of the C. moniliformis s.l. complex. Similar to other members of the C. moniliformis s.l. complex, $C$. salinaria and $C$. decipiens are characterized by fast growing cultures and they produce strong fruity (banana) odors on artificial media. Likewise, they produce ascomata with spiny bases and plate-like structures at the bases of the ascomatal necks as well as hat-shaped ascospores typical of species in the C. moniliformis s.l. complex. Most strains of $C$. salinaria sporulated readily on artificial media, producing ascomata and ascospore drops. In contrast, only one strain of $C$. decipiens sporulated on artificial media, and this strain ceased to sporulate after a single transfer to new media.

C. salinaria and C. decipiens differed in their growth rates, the length of their ostiolar hyphae and the widths of their necks. Minor morphological differences were also found between these newly described species and $C$. oblonga/C. savannae, which are their closest phylogenetic relatives. The 
ascomatal neck lengths of both $C$. salinaria and C. decipiens, as well as their bacilliform conidia were much shorter than those of $C$. oblonga and $C$. savannae. In addition, $C$. decipiens has necks with wider bases than those found in C. oblonga and C. savannae.

This study expands the host and geographic ranges of $C$. savannae to now include Eucalyptus trees. C. savannae was first described from native trees in South Africa in the absence of disease (Kamgan Nkuekam et al. 2008). In this study, C. savannae was isolated from wounds on two Eucalyptus species grown in the Soutpansberg area of South Africa, as well as from a staphylinid beetle and from two nitidulid beetles collected in this area. Previous reports of $C$. savannae were from the Kruger National Park and Leeuwfontein Collaborative Nature Reserve, both in the savanna regions in the eastern part of South Africa, similar to the Soutpansberg region. The discovery of C. savannae on Eucalyptus brings the substrates on which the fungus occurs to seven tree species, spanning six genera and four families. The origin of C. savannae is unknown and it is not known whether it is a native fungus that has spread from native trees to infect non-native Eucalyptus trees, most probably mediated by insect dispersal, or whether it is an introduced saprophyte that has adapted to native tree species.

C. oblonga was recently described from South Africa, associated with three nitidulid species, $B$. depressus, Ca. bisignatus and Ca. hemipterus collected from both native savanna regions and from plantations of non-native Acacia mearnsii trees (Heath et al. 2009b). It was, therefore, not surprising to find C. oblonga on Eucalyptus associated with two nitidulid beetles, B. depressus and an unidentified Carpophilus sp. Results of this study expand the substrates on which the fungus has been found in South Africa to include Eucalyptus trees and confirm the findings of Heath et al. (2009b) that nitidulid beetles are vectors of this fungus in South Africa.

Isolating C. moniliformis from Eucalyptus trees in this study was not surprising. The fungus has previously been reported from wounds on E. grandis trees in South Africa (Roux et al. 2004; Heath et al. 2009a) and Tanzania (Heath et al. 2009a). In this study, C. moniliformis was isolated from E. maculata grown in the Soutpansberg area and from E. grandis grown in the Sabie area. The fungus was also isolated from a staphylinid beetle infesting E. grandis trees in Sabie. This represents the first report of $C$. moniliformis from an insect and indicates that, like other Ceratocystis species, the fungus is also probably vectored by a wide variety of insects, including staphylinid beetles.

Similar to previous studies involving Eucalyptus trees, C. pirilliformis was commonly encountered. The fungus was first described from wounds made on eucalypts in Australia (Barnes et al. 2003a) and was later discovered occurring in the same niche in South Africa (Roux et al. 2004; Kamgan Nkuekam et al. 2009). The current study expands the geographic and host range of $C$. pirilliformis and it is now known from four Provinces in South Africa, spanning areas more than $2000 \mathrm{~km}$ distant from each other. This study represents the first report of $C$. pirilliformis from an insect. It indicates that, like other Ceratocystis species, the fungus is probably vectored by nitidulid insects. In recent population genetic 
studies of the fungus from South African collections, it was found that C. pirilliformis was probably introduced into South Africa, possibly from Australia, due to the low gene diversity and allelic richness of the fungus in South Africa (Kamgan Nkuekam et al. 2009).

C. zombamontana, first described from Eucalyptus trees in Malawi (Heath et al. 2009a) was reduced to synonymy with $C$. pirilliformis because analysis of DNA sequence data for five gene regions and morphological comparisons could not distinguish isolates from each other. The lack of resolution between isolates of $C$. zombamontana and $C$. pirilliformis in this study and not previously, most probably arose from the fact that additional strains of $C$. pirilliformis, both from Australia and South Africa have become available for comparison. This provided greater intra-species variation and thus an overlap between sequences for $C$. zombamontana and $C$. pirilliformis. Reconsideration of sequences used in previous studies to distinguish C. zombamontana from $C$. pirilliformis also revealed that differences in ITS for these species are found only in multiple repeat regions, thus providing little meaningful resolution. Allele networks for the ITS gene regions also supported the synonymy of $C$. pirilliformis and C. zombamontana.

Isolates of $C$. eucalypticola infecting eucalypts have a broad geographic distribution on these trees in South Africa. C. eucalypticola was first reported as C. fimbriata from three provinces (KwaZulu-Natal, Limpopo, Mpumalanga) spanning four different locations (KwaMbonambi, Haxyview/Wilgeboom, Paulpietersburg, Tzaneen) of South Africa (Van Wyk et al. 2006b). Isolates identified in this study originated from these same provinces where they were broadly collected in five different locations (Table 2, 3). Collections arising from this study report the association of C. eucalypticola with insects for the first time. It was interesting to find this fungus associated not only with nitidulid beetles but also with Xyleborus affinis which is a wood boring ambrosia beetle (Wood 1982). X. affinis is native to tropical America, but is now widely distributed worldwide, as well as in Africa (Rabaglia et al. 2006; Wood 1982) and this is the first record of a Ceratocystis sp. associated with it.

T. thielavioides causes root rot disease to various plant families in countries such as Brazil, Australia, Malaysia, Indonesia, North America and in Europe (Anonymous 2012). T. thielavioides was found for the first time in South Africa on two nitidulid species and it would be interesting to know whether it has been introduced into the country. The other Thielaviopsis sp. encountered, T. basicola was found on one nitidulid species. This is interesting because the fungus is known as a pathogen of several vegetable crops world-wide, including South Africa where it causes black pod rot of groundnuts (Arachis hypogaea L.) and black root rot of chicory (Cichorium intybus L.) (Prinsloo 1980; Prinsloo et al. 1991; Labuschagne and Kotze 1991; Geldenhuis et al. 2006). Population genetic studies using microsatellite markers have shown that two genotypes of T. basicola occur in South Africa, and that the fungus was most likely introduced into the country from Europe, probably through the distribution of root crops (Geldenhuis et al. 2006). Nitidulid beetles usually pupate in soil or in wood infested by fungi, and also 
feed on a wide variety of substrates such as flowers, stored crop products and fungi (Hinton 1945, Habeck 2002). These insects could have acquired the fungus from one of these substrates before flying to cut Eucalyptus stumps where they were collected. The results suggest that the fungus is able to leave the soil environment and infect above-ground parts of plants.

This study represents the first report of Ceratocystis species from insects in the Staphylinidae. Four Ceratocystis species, C. eucalypticola, C. moniliformis, C. decipiens and C. savannae were isolated from these insects. The Staphylinidae is one of the larger families of the Coleoptera (Lawrence and Newton 1995), which includes many predaceous and mycophagous species feeding mainly on macrofungi (Lawrence and Milner 1996). These insects are likely casual vectors of Ceratocystis species, with no fixed association given the number of Ceratocystis species that was isolated from them in a relatively limited study.

This study represents the most comprehensive consideration of Ceratocystis species and insects on Eucalyptus trees in South Africa. The number of species identified as well as insects from which they were isolated shows that the diversity of Ceratocystis species on Eucalyptus is still poorly understood in South Africa and even more so in other parts of the world. Future studies should explore the diversity of Ceratocystis species on native trees as well as on Eucalyptus trees in South Africa and in other African countries and will likely reveal numerous species of Ceratocystis, some of which could be important tree pathogens. Of the species collected in this study, several, including C. pirilliformis, C. moniliformis, $T$. basicola and T. thielavioides, have also been reported from other countries, including from Eucalyptus and other hosts, suggesting inter continental spread of these fungi. All the species collected in this study, as well as in a recent study of Ceratocystis species from Eucalyptus in Australia (Kamgan Nkuekam et al. 2012) produce fruity aromas, making them well-adapted for dispersal by various insects, including those living in the wood, bark and below the bark of trees. They can thus easily be spread on timber and other plant material and should all be considered important quarantine threats.

\section{Acknowledgements}

We thank the National Research Foundation of South Africa (NRF), the THRIP Initiative of the Department of Trade and Industry (THRIP/DST), members of the Tree Protection Co-operative Programme (TPCP) and the University of Pretoria for funding and the facilities to undertake this study. Dr. Andrew Cline and Dr. Roger Beaver from the USA are thanked for assisting us with the identification of insects collected in this study. Prof. Goeneveld and Dr. Van der Linde from the Department of Statistics and Mr. Alan Hall of the Electron Microscopy Unit, University of Pretoria are thanked for their assistance with the statistical analyses and scanning electron microscopy, respectively. We further thank Dr. Hugh Glen who provided the Latin diagnoses and made suggestions for the names of the new taxa. 
Staffs of member companies of the TPCP are thanked for their assistance in identifying field sites for surveys and assistance during the surveys.

\section{References}

Anonymous (2012) Nomenclature Fact Sheets - Systematic Mycology and Microbiology Laboratory, United States Department of Agriculture (USDA)

Barnes I, Dudzinski MJ, Old KM, Roux J, Wingfield BD, Wingfield MJ (2003a) Ceratocystis pirilliformis, a new species from Eucalyptus nitens in Australia. Mycologia 95:865-871

Barnes I, O’Neill M, Roux J, Wingfield BD, Wingfield MJ (2003b) Ceratocystis fimbriata infecting Eucalyptus grandis in Uruguay. Australas Plant Pathol 32:361-366

Cease KR, Juzwik J (2001) Predominant nitidulid species (Coleoptera: Nitidulidae) associated with spring oak wilt mats in Minnesota. Can J Forest Res 31:635-643

Clement M, Posada D, Crandall K (2000) TCS: a computer program to estimate gene genealogies. Mol Ecol 9:1657-1660

Fergusson NDM (1982) Pooter post. Antenna 6:282-284

Ferreira FA, Demuner AM, Demuner NL, Pigatto S (1999) Murchade-Ceratocystis em eucalipto no Brasil. Fitopatol Bras 24: 284

Glass NL, Donaldson GC (1995) Development of primer sets designed for use with the PCR to amplify conserved genes from filamentous Ascomycetes. Appl Environ Microbiol 61:1323-1330

Gorter GJMA (1977) Index of plant pathogens and the diseases they cause in cultivated plants in South Africa. Science Bulletin no. 392. Pretoria, South Africa: Plant Protection Research Institute, Department of Agricultural Technical Services

Geldenhuis MM, Roux J, Cilliers AJ, Wingfield BD, Wingfield MJ (2006) Clonality in South African isolates and evidence for a European origin of the root pathogen Thielaviopsis basicola. Mycol Res 110:306-311

Grobbelaar J, Aghayeva D, De Beer ZW, Bloomer P, Wingfield MJ, Wingfield BD (2009) Delimitation of Ophiostoma quercus and its synonyms using multiple gene phylogenies. Mycol Prog 8:221236

Guindon S, Gascuel O (2003) A simple, fast, and accurate algorithm to estimate large phylogenies by maximum likelihood. Systematic Biol 52:696-704

Habeck D (2002) Nitidulidae Latrielle 1802. In: Arnett RH, Thomas MC, Skelley PE, Howard Frank J (eds) American Beetles Volume 2. Polyphaga: Scarabaeoidea through Curculionoidea. CRC Press, Boca Raton, pp 311-315 
Halsted BD (1890) Some fungus diseases of the sweet potato. The black rot. New Jersey Agric Exp Sta Bull 76:7-14

Halsted BD, Fairchild DG (1891) Sweet potato black rot. J Mycol 7:1-11

Hayslett M, Juzwik J, Moltzan B (2007) Three Coleopterus beetle species carry the Oak wilt fungus to fresh wounds on red Oak in Missouri. Plant Dis 92:270-275

Harrington TC, Wingfield MJ (1998) The Ceratocystis species on conifers. Can J Bot 76:1446-1457

Heath RN, Wingfield MJ, Wingfield BD, Meke G, Mbaga A, Roux J (2009a) Ceratocystis species on Acacia mearnsii and Eucalyptus spp. in eastern and southern Africa including six new species. Fungal Divers 34:41-68

Heath RN, Van Wyk M, Roux J, Wingfield MJ (2009b) Insect associates of Ceratocystis albifundus and patterns of association in a native savanna ecosystem in South Africa. Environ Entomol 38:356364

Hinton HE (1945) A monograph of the beetles associated with stored products. Vol 1, London, British Museum

Huelsenbeck JP, Bull JJ, Cunningham CW (1996) Combining data in phylogenetic analysis. Tree $11: 152-158$

Huelsenbeck JP, Ronquist F (2001) MRBAYES: Bayesian inference of phylogenetic trees. Bioinformatics 17:754

Jacobs K, Bergdahl DR, Wingfield MJ, Halik S, Seifert KA, Bright DE, Wingfield BD (2004) Leptographium wingfieldii introduced into North America and found associated with exotic Tomicus piniperda and native bark beetles. Mycol Res 108:411-418

Juzwik J, Skalbeck TC, Neuman MF (2004) Sap beetle species (Coleoptera: Nitidulidae) visiting fresh wounds on healthy Oaks during spring in Minnesota. Forest Sci 50:757-764

Juzwik J, Harrington TC, MacDonald WL, Appel DN (2008) The origin of Ceratocystis fagacearum, the oak wilt fungus. Annu Rev Phytopathol 46:13-26

Kamgan Nkuekam G, Barnes I, Wingfield MJ, Roux J (2009) Distribution and population diversity of Ceratocystis pirilliformis in South Africa. Mycologia 101:17-25

Kamgan Nkuekam G, Jacobs K, De Beer ZW, Wingfield MJ, Roux J (2008) Ceratocystis and Ophiostoma species, including three new taxa, associated with wounds on native South African trees. Fungal Divers 29:37-59

Kamgan Nkuekam G, Wingfield MJ, Mohammed C, Carnegie AJ, Pegg GS, Roux J (2012) Ceratocystis species, including two new species associated with nitidulid beetles on eucalypts in Australia. Anton van Lee 101:217-241

Katoh K, Toh H (2008) Recent developments in the MAFFT multiple sequence alignment program. Brief Bioinform 9:286-298 
Kile GA (1993) Plant diseases caused by species of Ceratocystis sensu stricto and chalara. In: Wingfield MJ, Seifert KA, Webber JF (eds) Ceratocystis and Ophiostoma: Taxonomy, Ecology and Pathogenicity. American Phytopathological Society Press, St. Paul, Minesota, pp 173-183

Kile GA, Dudzinski MJ, Harrington TC, Old KM, Yuan ZQ (1996) Ceratocystis eucalypti sp. nov., a vascular stain fungus from eucalyps in Australia. Mycol Res 100:571-579

Labuschagne N, Kotze JM (1991) Incidence of Chalara elegans in groundnut seed samples and seed transmission of blackhull. Plant Pathol 40:639-642

Lawrence JF, Milner RJ (1996) Associations between arthropods and fungi. In: Orchard AE (ed) fungi of Australia. Volume IB. Introduction - fungi in the Environment. Australian Biological Ressources Study, Canberra, pp 137-202

Lawrence JF, Newton AF Jr (1995) Families and subfamilies of Coleoptera (with selected genera, notes, references and data on family-group names). In: Pakaluk J, Slipinski SA (eds) Biology, Phylogeny and Classification of Coleoptera: Papers celebrating the $80^{\text {th }}$ birthday of Roy A. Crowson. Muzeum i Instytut Zoologii PAN, Warszawa, Poland, pp 779-1006

Marin M, Preisig O, Wingfield BD, Kirisits T, Yamaoka Y, Wingfield MJ (2005) Phenotypic and DNA sequence data comparisons reveal three discrete species in the Ceratocystis polonica species complex. Mycol Res 109:1137-1148

Moller WJ, Devay JE (1968) Insect transmission of Ceratocystis fimbriata in deciduous fruit orchards. Phytopathology 58:1499-1507

Morris MJ, Wingfield MJ, De Beer C (1993) Gummosis and wilt of Acacia mearnsii in South Africa caused by Ceratocystis fimbriata. Plant Pathol 42:814-817

Panconesi A (1999) Canker stain of plane trees: A serious danger to urban plantings in Europe. J Plant Pathol 81:3-15

Podlaha O, Zhang J (2010) Pseudogenes and their evolution. In: Wiley J \& Sons (eds) Encyclopedia of life sciences (ELS), Ltd: Chichester. Doi: 10.1002/9780470015902.a0005118.pub2

Posada D, Crandall KA (1998) MODELTEST: testing the model of DNA substitution. Bioinformatics 14:817-818

Prinsloo GC (1980) Thielaviopsis basicola associated with a pod disease of groundnuts in South Africa. Phytophylactica 12:25-26

Prinsloo GC, Baard SW, Ferreira JF (1991) Organisms associated with black root rot of chicory in South Africa. Phytophylactica 23:59-67

Rabaglia R, Dole SE, Cognato AI (2006) Review of America Xyleborina (Coleoptera: Curculionidae: Scolytinae) Occurring north of Mexico, with an illustrated key. Ann Entomol Soc Am 99:10341056 
Rayner RW (1970) A mycological colour chart. Commonwealth Mycological Institute and British Mycological Society, Kew, Surrey

Rodas C.A, Roux J, van Wyk M, Wingfield B.D, Wingfield MJ (2008) Ceratocystis neglecta sp. nov., infecting Eucalyptus trees in Colombia. Fungal Divers 28:73-84

Rouchka EC, Cha IE (2009) Current trends in pseudogene detection and characterization. Curr Bioinform 4:112-119

Roux J, Wingfield MJ (2009) Ceratocystis species: emerging pathogens of non-native plantation Eucalyptus and Acacia species. South Forests 72:115-120

Roux J, Alfenas AC, Bouillet JP, Wingfield MJ, Wingfield BD (1999) A serious new wilt disease of Eucalyptus caused by Ceratocystis fimbriata in Central Africa. Forest Pathol 30:175-184

Roux J, Coutinho TA, Mujuni BD, Wingfield MJ (2001) Diseases of plantation Eucalyptus in Uganda. S Afr J Sci 97:16-18

Roux J, Van Wyk M, Hatting H, Wingfield MJ (2004) Ceratocystis species infecting stem wounds on Eucalyptus grandis in South Africa. Plant Pathol 53:414-421

Roux J, Heath RN, Labuschagne L, Kamgan Nkuekam G, Wingfield MJ (2007) Occurrence of the wattle wilt pathogen, Ceratocystis albifundus on native South African trees. Forest Pathol 37:292-302

SAS Institute Inc., SAS/STAT Users Guide, Version 8, Cary NC: SAS Institute Inc., 1999. ISBN 158025-494-2

Swofford DL (1998) PAUP. Phylogenetic analysis using parsimony (and other methods). Version 4. Sinaur Associates, Sunderland, Massachusetts

Sinclair WA, Lyon HH (2005) Diseases of trees and shrubs $2^{\text {nd }}$ Edition. Cornell University Press: Ithaca, London, pp 232-241

Tamura K, Dudley J, Nei M, Kumar S (2007) MEGA4: Molecular Evolutionary Genetics Analysis (MEGA) software version 4.0. Mol Biol Evol 24:1596-1599

Van Wyk M, Barnes I, Roux J, Wingfield BD, Wingfield MJ (2006a) Molecular phylogeny of the Ceratocystis moniliformis complex and description of C. tribiliformis sp. nov. Fungal Divers 21:181-201

Van Wyk M, Van der Merwe NA, Roux J, Wingfield BD, Kamgan Nkuekam G, Wingfield MJ (2006b) Population biology of Ceratocystis fimbriata from Eucalyptus trees in South Africa. S Afr J Sci 102:259-263

Van Wyk M, Pegg G, Lawson S, Wingfield MJ (2007a) Ceratocystis atrox sp. nov associated with Phoracanthta acanthocera infestations on Eucalyptus grandis in Australia. Australas Plant Pathol 36:407-414 
Van Wyk M, Al Adawi AO, Khan IA, Deadman ML, Al Jahwari AA, Wingfield BD, Ploetz R, Wingfield MJ (2007b) Ceratocystis manginecans sp. nov, causal agent of a destructive mango wilt disease in Oman and Pakistan. Fungal Divers 27:213-230

Van Wyk M, Wingfield BD, Mohali S, Wingfield MJ (2009) Ceratocystis fimbriatomima, a new species in the C. fimbriata sensu lato complex isolated from Eucalyptus trees in Venezuela. Fungal Divers 34:173-183

Van Wyk M, Wingfield BD, Wingfield MJ (2011) Four new Ceratocystis spp. associated with wounds on Eucalyptus, Schizolobium and Terminalia trees in Ecuador. Fungal Divers 46: 111-131

Van Wyk M, Wingfield BD, Roux J, Kamgan Nkuekam G, Wingfield MJ (2012) Ceratocystis eucalypticola sp. Nov. from Eucalyptus in South Africa and comparison to global isolates from this tree. IMA Fungus 3:45-58

Wood SL (1982) The bark and ambrosia beetles of North and Central America (Coleoptera: Scolytidae), a taxonomic monograph. Great Basin Nat Memoirs 6:1-1356

Walter JM, Rex EG, Schreiber R (1952) The rate of progress and destructiveness of canker stain of plane trees. Phytopathology 42:236-239

White TJ, Bruns T, Lee S, Taylor J (1990) Amplification and direct sequencing of fungal ribosomal RNA genes for phylogenetics. In: Innis MA, Gelfand DH, Sninsky JJ, White TJ (eds) PCR Protocols: A sequencing guide to methods and applications. Academic Press, San Diego, pp $315-322$

Wingfield MJ, De Beer C, Visser C, Wingfield BD (1996) A new Ceratocystis species defined using morphological and ribosomal DNA sequence comparisons. Syst Appl Microbiol 19:191-202

Wingfield MJ, Harrington TC, Solheim H (1997) Two species in the Ceratocystis coerulescens complex from conifers in western North America. Can J Bot 75:827-834 
Table 1 Best fit models of evolution for each gene region used in distance analyses (Bayesian and Maximum Likelihood)

\begin{tabular}{|c|c|c|c|c|c|}
\hline & Type of Analyses & ITS & BT1 & TEF & Combined tree \\
\hline \multirow[t]{2}{*}{ C. fimbriata s.l. } & Bayesian & $\mathrm{GTR}+\mathrm{G}$ & $\mathrm{HKY}+\mathrm{I}$ & HKY & $\mathrm{GTR}+\mathrm{I}+\mathrm{G}$ \\
\hline & Maximum likelihood & $\begin{array}{l}\text { TVM }+ \text { G }(\text { Rates }=\text { gamma, } \\
\text { Shape }=0.3029, \text { Pinvar }=0)\end{array}$ & $\begin{array}{l}\text { TrN+I (Rates=equal, } \\
\text { Pinvar }=0.5812)\end{array}$ & $\begin{array}{l}\text { TrN }(\text { Rates=equal, } \\
\text { Pinvar=0) }\end{array}$ & $\begin{array}{l}\text { TVM }+\mathrm{I}+\mathrm{G}(\text { Rates }=\text { gamma, } \\
\text { Shape }=0.5904, \\
\text { Pinvar }=0.3169)\end{array}$ \\
\hline \multirow[t]{2}{*}{ C. moniliformis s. $l$. } & Bayesian & $\mathrm{HKY}+\mathrm{I}$ & $\mathrm{HKY}+\mathrm{I}$ & $\mathrm{K} 80+\mathrm{I}$ & $(\mathrm{HKY}+\mathrm{I})$ \\
\hline & Maximum likelihood & $\begin{array}{l}\mathrm{HKY}+\mathrm{I}(\text { Rates }=\text { equal, } \\
\text { Pinvar }=0.9261)\end{array}$ & $\begin{array}{l}\mathrm{TrN}+\mathrm{I}(\text { Rates=equal, } \\
\text { Pinvar }=0.8006)\end{array}$ & $\begin{array}{l}\text { K80+I (Rates=equal, } \\
\text { Pinvar }=0.4669)\end{array}$ & $\begin{array}{l}\mathrm{HKY}+\mathrm{I}(\text { Rates }=\text { equal, } \\
\text { Pinvar=0.8017) }\end{array}$ \\
\hline
\end{tabular}


Table 2 Fungi isolated from Eucalyptus trees during surveys in South Africa

\begin{tabular}{|c|c|c|c|c|c|c|c|}
\hline Provinces & Locations & $\begin{array}{l}\text { Climatic } \\
\text { Types }\end{array}$ & CMW & $\begin{array}{l}\text { Number of } \\
\text { Isolates }\end{array}$ & ID & $\begin{array}{l}\text { Morpho- } \\
\text { group }\end{array}$ & Hosts \\
\hline Eastern Cape & Lotobeni & temperate & $28204,28205,28206$ & 3 & C. pirilliformis & A2 & E. grandis \\
\hline$"$ & Kumbo & temperate & 27181,27182 & 2 & C. pirilliformis & A2 & E. grandis \\
\hline KwaZulu-Natal & KwaMbonambi & subtropical & $\begin{array}{l}24984,24975,24976,24979,24980, \\
24974,24952\end{array}$ & 7 & C. eucalypticola & A1 & Eucalyptus sp. \\
\hline$"$ & Pietermaritzburg & subtropical & $\begin{array}{l}24955,24957,24958,24960,24961, \\
24962,24963,24965,24967,24969, \\
24970,24972\end{array}$ & 12 & C. eucalypticola & A1 & Eucalyptus sp. \\
\hline Limpopo & Goedehoop & subtropical & 26472,26466 & 2 & C. pirilliformis & A2 & E. cloeziana \\
\hline$"$ & Soutpansberg & subtropical & $\begin{array}{l}30888,30860,30889,30861,30890, \\
30891\end{array}$ & 6 & C. eucalypticola & A1 & E. saligna \\
\hline$"$ & Soutpansberg & subtropical & 30701 & 1 & C. decipiens & B & E. saligna \\
\hline$"$ & Soutpansberg & subtropical & 25914 & 1 & C. decipiens & B & E. maculata \\
\hline$"$ & Goedehoop & subtropical & 25918,25919 & 2 & C. decipiens & B & E. cloeziana \\
\hline$"$ & Goedehoop & subtropical & 25920 & 1 & C. savannae & B & E. cloeziana \\
\hline$"$ & Soutpansberg & subtropical & $25909,25915,25916$ & 3 & C. savannae & B & E. maculata \\
\hline$"$ & Soutpansberg & subtropical & $25910,25911,25913$ & 3 & C. salinaria & B & E. maculata \\
\hline$"$ & Goedehoop & subtropical & 25917 & 1 & C. salinaria & B & E. cloeziana \\
\hline$"$ & Soutpansberg & subtropical & $30702,30703,30704$ & 3 & C. salinaria & B & E. saligna \\
\hline$"$ & Soutpansberg & subtropical & 25912 & 1 & C. moniliformis & B & E. maculata \\
\hline Mpumalanga & Sabie & subtropical & $\begin{array}{l}\text { 30892, 30893, 30894, 30895, 30896, } \\
30897,30898\end{array}$ & 7 & C. eucalypticola & A1 & E. grandis \\
\hline$"$ & Sabie & subtropical & 30698 & 1 & C. oblonga & B & E. grandis \\
\hline$"$ & Sabie & subtropical & 30699,30700 & 2 & C. moniliformis & B & E. grandis \\
\hline Limpopo & Tzaneen & subtropical & $\begin{array}{l}25001,24991,24989,24998,24994, \\
25012,25008,25025,25021,25019, \\
25017,25015,25023\end{array}$ & 13 & C. eucalypticola & A1 & E. grandis \\
\hline Western Cape & Cape Town & mediteranean & 28200,29822 & 2 & C. pirilliformis & A2 & Eucalyptus logs \\
\hline$"$ & Cape Town & mediteranean & 27162,27163 & 2 & C. pirilliformis & A2 & E. diversicolor \\
\hline$"$ & Cape Town & mediteranean & $\begin{array}{l}27183,27184,27185,27186,27187, \\
27188\end{array}$ & 6 & C. pirilliformis & A2 & E. saligna \\
\hline$"$ & George & mediteranean & $\begin{array}{l}27047,27155,27048,27157,27049, \\
27050,27051,27052,27053,27054, \\
27259,27055,27153,27158,27156,\end{array}$ & 17 & C. pirilliformis & A2 & Eucalyptus sp. \\
\hline$"$ & George & mediteranean & 27006,27007 & 2 & C. salinaria & B & Eucalyptus sp. \\
\hline Total & & & & 100 & & & \\
\hline
\end{tabular}


Table 3 Fungi isolated from insects infesting Eucalyptus stumps during surveys in South Africa




Table 4 List of Ceratocystis isolates used in comparative morphological and phylogenetic studies

\begin{tabular}{|c|c|c|c|c|c|c|c|}
\hline Isolate designation & $\begin{array}{l}\text { Isolate } \\
\text { number }\end{array}$ & Genbank & $\begin{array}{l}\text { Gene } \\
\text { regions }\end{array}$ & Other numbers & Hosts & Collectors & Origin \\
\hline \multirow[t]{3}{*}{ C. acaciivora } & CMW22563 & EU588656 & ITS & NA & Acacia mangium & M. Tarigan & Indonesia \\
\hline & & EU588636 & BT1 & $"$ & $"$ & $"$ & $"$ \\
\hline & & EU588646 & TEF & $"$ & $"$ & $"$ & $"$ \\
\hline \multirow[t]{3}{*}{ C. albifundus } & CMW4068 & DQ520638 & ITS & CBS 128992 & A. mearnsii & J. Roux & South Africa \\
\hline & & EF070429 & BT1 & $"$ & $"$ & $"$ & $"$ \\
\hline & & EF070400 & TEF & $"$ & $"$ & $"$ & $"$ \\
\hline \multirow[t]{3}{*}{ C. aracearum } & CMW14805 & AY 526297 & ITS & CBS 115165 & Colocasia esculenta & C.J.B. Engelbrecht & Costa Rica \\
\hline & & GU810160 & BT1 & $"$ & $"$ & $"$ & $"$ \\
\hline & & GU810166 & TEF & $"$ & $"$ & $"$ & $"$ \\
\hline \multirow[t]{3}{*}{ C. atrox } & CMW19385 & EF070415 & ITS & CBS 120518 & E. grandis & M.J. Wingfield & Australia \\
\hline & & EF070431 & BT1 & $"$ & $"$ & $"$ & $"$ \\
\hline & & EF070403 & TEF & $"$ & $"$ & $"$ & $"$ \\
\hline \multirow[t]{3}{*}{ C. belula } & CMW14811 & AY 526288 & ITS & CBS 115171 & C. esculenta & T.C. Harrington & Brazil \\
\hline & & GU810162 & BT1 & $"$ & $"$ & $"$ & $"$ \\
\hline & & GU810168 & TEF & $"$ & $"$ & $"$ & $"$ \\
\hline \multirow[t]{7}{*}{ C. bhutanensis } & CMW8399 & AY528959 & ITS & CBS 115772, BH 8/8 & Picea spinulosa & T. Kirisits \& D.B. Chhetri & Bhutan \\
\hline & & AY528964 & BT1 & $"$ & $"$ & $"$ & $"$ \\
\hline & & AY 528954 & TEF & $"$ & $"$ & $"$ & $"$ \\
\hline & CMW8215 & AY 528958 & ITS & CBS114290, & $"$ & T. Kirisits \& D.B. Chhetri & Bhutan \\
\hline & & & & PREM57805 & & & \\
\hline & & AY528963 & BT1 & " & $"$ & $"$ & $"$ \\
\hline & & AY 528953 & TEF & $"$ & $"$ & $"$ & $"$ \\
\hline \multirow[t]{3}{*}{ C. cacaofunesta } & CMW15051 & DQ520636 & ITS & CBS 152.62 & Theobroma cacao & A.J. Hansen & Costa Rica \\
\hline & & EF070427 & BT1 & $"$ & $"$ & $"$ & $"$ \\
\hline & & EF070398 & TEF & $"$ & $"$ & $"$ & $"$ \\
\hline \multirow[t]{3}{*}{ C. caryae } & CMW14793 & EF070424 & ITS & CBS 114716 & Carya cordiformis & J. Johnson & USA \\
\hline & & EF070439 & BT1 & $"$ & $"$ & $"$ & $"$ \\
\hline & & EF070412 & TEF & $"$ & $"$ & $"$ & $"$ \\
\hline \multirow[t]{3}{*}{ C. colocasiae } & CMW14796 & AY 526307 & ITS & CBS 114720 & Colocasia esculenta & J. Uchida & USA \\
\hline & & GU810164 & BT1 & $"$ & $"$ & $"$ & $"$ \\
\hline & & GU810170 & TEF & $"$ & $"$ & $"$ & $"$ \\
\hline \multirow[t]{3}{*}{ C. colombiana } & CMW5751 & AY177233 & ITS & CBS 121792 & Coffea arabica & M. Marin & Colombia \\
\hline & & AY 177225 & BT1 & $"$ & $"$ & $"$ & $"$ \\
\hline & & EU241493 & TEF & $"$ & $"$ & $"$ & $"$ \\
\hline \multirow[t]{3}{*}{ C. corymbiicola } & CMW29120 & HM071902 & ITS & CBS 127215 & Corymbia variegata & G.N. Kamgan & Australia \\
\hline & & HM071914 & BT1 & $"$ & $"$ & $"$ & $"$ \\
\hline & & HQ236453 & TEF & $"$ & $"$ & $"$ & $"$ \\
\hline \multirow[t]{3}{*}{ C. curvata } & CMW22442 & FJ151436 & ITS & CBS 122603 & E. deglupta & M.J. Wingfield & Colombia \\
\hline & & FJ151448 & BT1 & $"$ & $"$ & $"$ & $"$ \\
\hline & & FJ151470 & TEF & $"$ & $"$ & $"$ & $"$ \\
\hline \multirow[t]{8}{*}{ C. decipiens } & CMW30855 & HQ203216 & ITS & CBS 129736 & Staphilinid. sp. & G.N. Kamgan \& J. Roux & South Africa \\
\hline & & HQ203233 & BT1 & $"$ & $"$ & $"$ & $"$ \\
\hline & & HQ236435 & TEF & $"$ & $"$ & $"$ & $"$ \\
\hline & CMW25918 & HQ203218 & ITS & CBS129735 & E. cloeziana & $"$ & $"$ \\
\hline & & HQ203235 & BT1 & $"$ & $"$ & $"$ & $"$ \\
\hline & & HQ236437 & TEF & $"$ & $"$ & $"$ & $"$ \\
\hline & CMW25914 & HQ203219 & ITS & CBS 129737 & E. maculata & $"$ & $"$ \\
\hline & & HQ203236 & BT1 & $"$ & $"$ & $"$ & $"$ \\
\hline
\end{tabular}




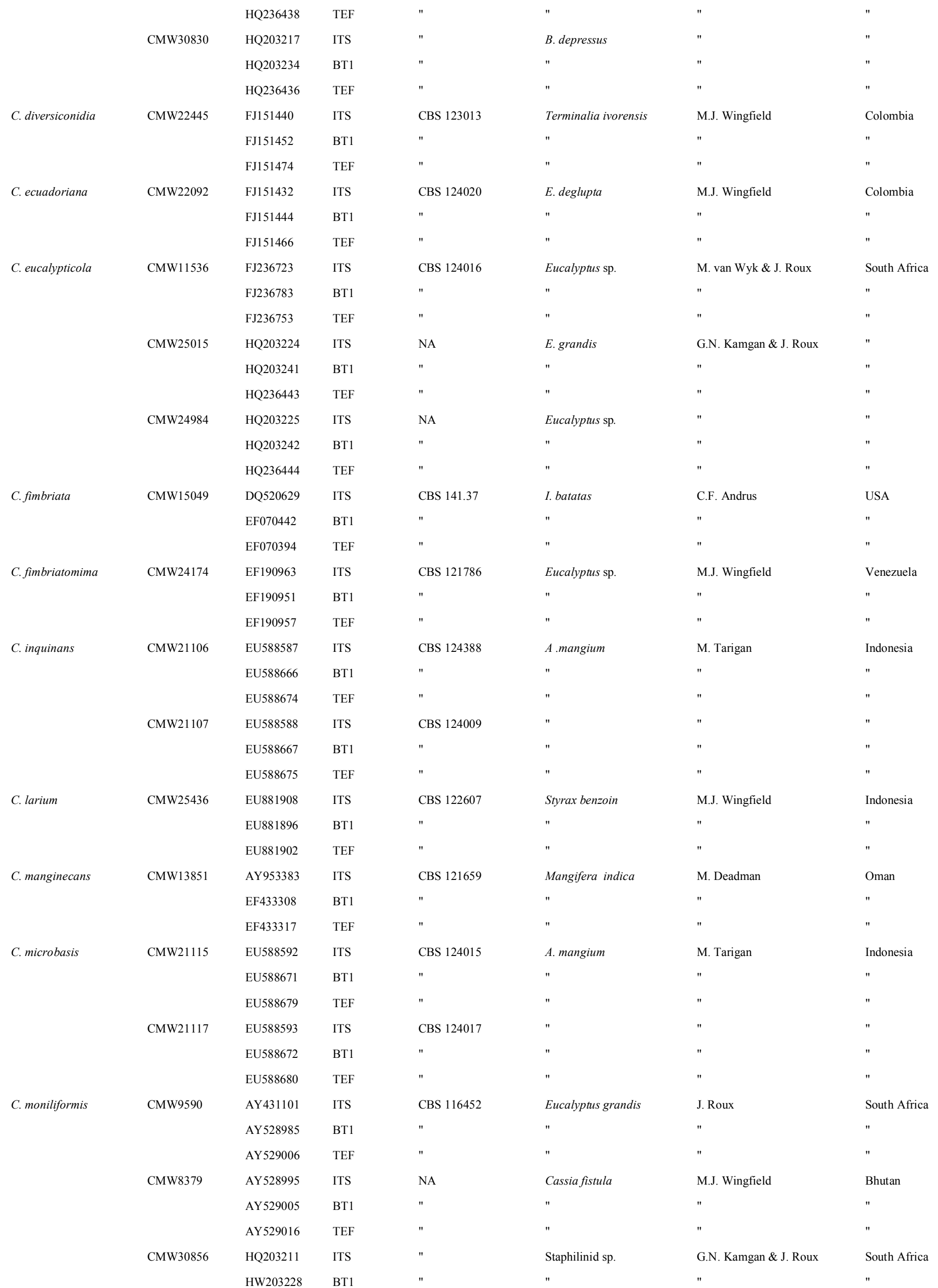




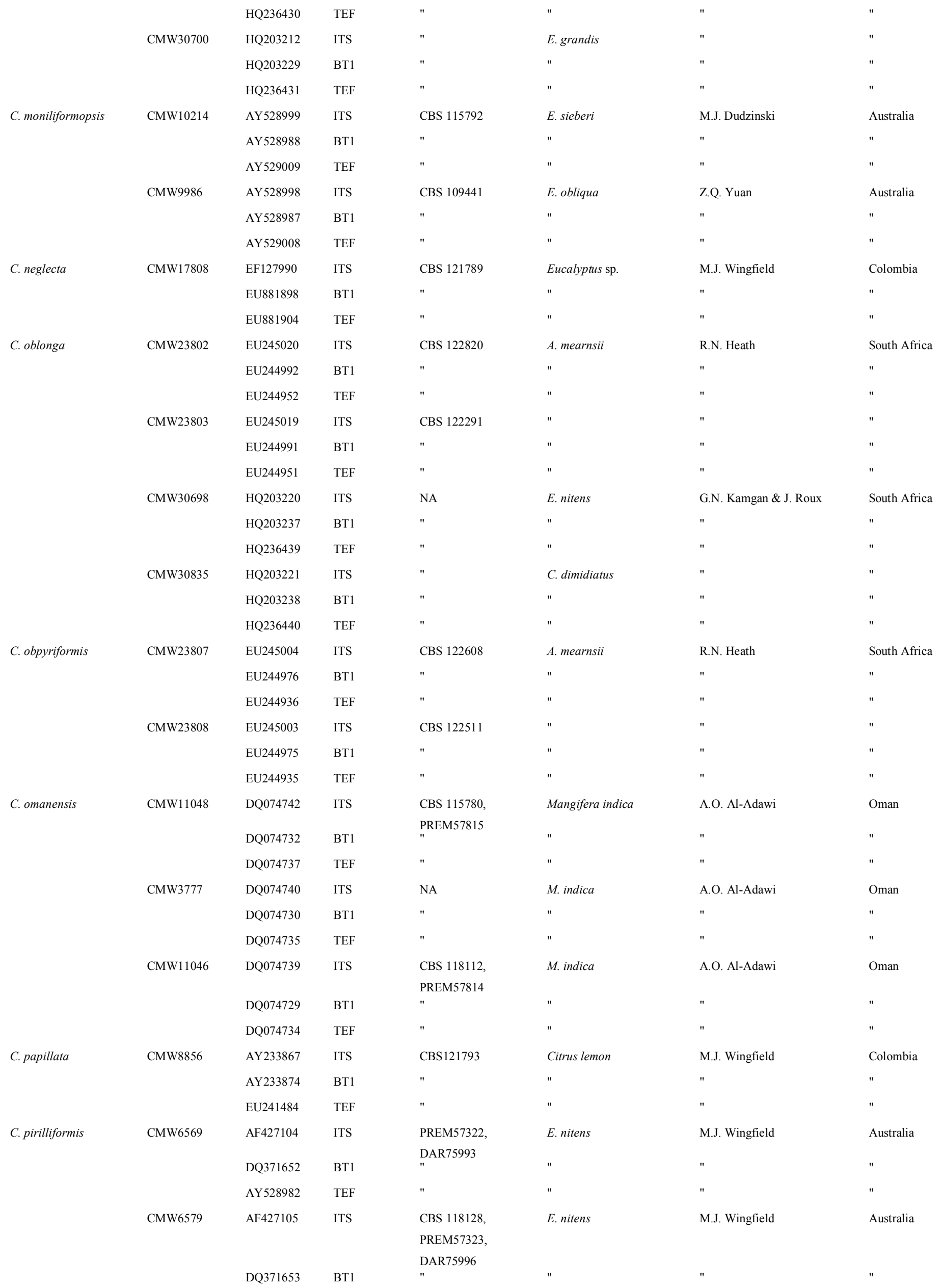




\begin{tabular}{|c|c|c|c|c|c|c|c|}
\hline & & AY528983 & TEF & $"$ & $"$ & $"$ & $"$ \\
\hline & \multirow[t]{3}{*}{ CMW29822 } & HQ203227 & ITS & NA & Eucalyptus $\log$ & G.N. Kamgan \& J. Roux & South Africa \\
\hline & & HQ203244 & BT1 & $"$ & $"$ & $"$ & $"$ \\
\hline & & HQ236446 & TEF & $"$ & $"$ & $"$ & $"$ \\
\hline & \multirow[t]{3}{*}{ CMW29825 } & HQ203226 & ITS & $"$ & B. depressus & $"$ & $"$ \\
\hline & & HQ203243 & BT1 & $"$ & $"$ & $"$ & $"$ \\
\hline & & HQ236445 & TEF & $"$ & $"$ & $"$ & $"$ \\
\hline \multirow[t]{3}{*}{ C. platani } & \multirow[t]{3}{*}{ CMW14802 } & DQ520630 & ITS & CBS 115162 & Platanus occidentalis & T.C. Harrington & USA \\
\hline & & EF070425 & BT1 & $"$ & $"$ & $"$ & $"$ \\
\hline & & EF070396 & TEF & $"$ & $"$ & $"$ & $"$ \\
\hline \multirow[t]{3}{*}{ C. polychroma } & \multirow[t]{3}{*}{ CMW11424 } & AY528983 & ITS & CBS 115778 & Syzygium aromaticum & E.C.Y. Liew \& M.J. & Indonesia \\
\hline & & AY528966 & BT1 & $\begin{array}{l}\text { PREM57818 } \\
"\end{array}$ & $"$ & $\begin{array}{l}\text { Wingfield } \\
"\end{array}$ & $"$ \\
\hline & & AY528970 & TEF & $"$ & $"$ & $"$ & $"$ \\
\hline \multirow[t]{6}{*}{ C. polyconidia } & \multirow[t]{3}{*}{ CMW23809 } & EU245006 & ITS & CBS 122289 & A. mearnsii & R.N. Heath & South Africa \\
\hline & & EU244978 & BT1 & $"$ & $"$ & $"$ & $"$ \\
\hline & & EU244938 & TEF & $"$ & $"$ & $"$ & $"$ \\
\hline & \multirow[t]{3}{*}{ CMW23818 } & EU245007 & ITS & CBS 122290 & $"$ & $"$ & $"$ \\
\hline & & EU244979 & BT1 & $"$ & $"$ & $"$ & $"$ \\
\hline & & EU244939 & TEF & $"$ & $"$ & $"$ & $"$ \\
\hline \multirow[t]{3}{*}{ C. populicola } & \multirow[t]{3}{*}{ CMW14789 } & EF070418 & ITS & CBS 119.78 & Populus sp. & J. Gremmen & Poland \\
\hline & & EF070434 & BT1 & $"$ & $"$ & $"$ & $"$ \\
\hline & & EF070406 & TEF & $"$ & $"$ & $"$ & $"$ \\
\hline \multirow[t]{9}{*}{ C. salinaria } & \multirow[t]{3}{*}{ CMW25911 } & HQ203213 & ITS & CBS 129733 & E. maculata & G.N. Kamgan \& J. Roux & South Africa \\
\hline & & HQ203230 & BT1 & $"$ & $"$ & $"$ & $"$ \\
\hline & & HQ236432 & TEF & $"$ & $"$ & $"$ & $"$ \\
\hline & \multirow[t]{3}{*}{ CMW30702 } & HQ203215 & ITS & NA & E. saligna & $"$ & $"$ \\
\hline & & HQ203232 & BT1 & $"$ & $"$ & $"$ & $"$ \\
\hline & & HQ236434 & TEF & $"$ & $"$ & $"$ & $"$ \\
\hline & \multirow[t]{3}{*}{ CMW30703 } & HQ203214 & ITS & CBS 129734 & E. saligna & $"$ & $"$ \\
\hline & & HQ203231 & BT1 & $"$ & $"$ & $"$ & $"$ \\
\hline & & HQ236433 & TEF & $"$ & $"$ & $"$ & $"$ \\
\hline \multirow[t]{12}{*}{ C. savannae } & \multirow[t]{3}{*}{ CMW17300 } & EF408551 & ITS & CBS 121151 & Acacia nigrescens & G.N. Kamgan \& J. Roux & South Africa \\
\hline & & EF408565 & BT1 & $"$ & $"$ & $"$ & $"$ \\
\hline & & EF408572 & TEF & $"$ & $"$ & $"$ & $"$ \\
\hline & \multirow[t]{3}{*}{ CMW17297 } & EF408552 & ITS & CBS 121021 & Combretum zeyheri & G.N. Kamgan \& J. Roux & South Africa \\
\hline & & EF408566 & BT1 & $"$ & $"$ & $"$ & $"$ \\
\hline & & EF408573 & TEF & $"$ & $"$ & $"$ & $"$ \\
\hline & \multirow[t]{3}{*}{ CMW30828 } & HQ203223 & ITS & $"$ & B. depressus & G.N. Kamgan \& J. Roux & South Africa \\
\hline & & HQ203240 & BT1 & $"$ & $"$ & " & $"$ \\
\hline & & HQ236442 & TEF & $"$ & $"$ & $"$ & $"$ \\
\hline & \multirow[t]{3}{*}{ CMW30846 } & HQ203222 & ITS & $"$ & C. dimidiatus & $"$ & $"$ \\
\hline & & HQ203239 & BT1 & $"$ & $"$ & $"$ & $"$ \\
\hline & & HQ236441 & TEF & $"$ & $"$ & " & $"$ \\
\hline C. smalleyi & CMW14800 & EF070420 & ITS & CBS 114724 & Carya cordiformis & G. Smalley & USA \\
\hline & & EF070436 & BT1 & $"$ & $"$ & $"$ & $"$ \\
\hline & & EF070408 & TEF & $"$ & $"$ & $"$ & $"$ \\
\hline C. sumatrana & CMW21109 & EU588589 & ITS & CBS 124011 & A.mangium & M. Tarigan & Indonesia \\
\hline & & EU588668 & BT1 & $"$ & $"$ & $"$ & $"$ \\
\hline & & EU588676 & TEF & $"$ & $"$ & $"$ & $"$ \\
\hline & CMW21111 & EU588590 & ITS & CBS 124012" & $"$ & $"$ & $"$ \\
\hline
\end{tabular}




\begin{tabular}{|c|c|c|c|c|c|c|c|}
\hline & & EU588669 & BT1 & $"$ & $"$ & $"$ & $"$ \\
\hline & & EU588677 & TEF & $"$ & $"$ & $"$ & $"$ \\
\hline \multirow[t]{3}{*}{ C. tanganyicensis } & CMW15992 & EU244999 & ITS & CBS 122293 & A. mearnsii & R.N. Heath \& J. Roux & Tanzania \\
\hline & & EU244971 & BT1 & $"$ & $"$ & $"$ & $"$ \\
\hline & & EU244931 & TEF & $"$ & $"$ & $"$ & $"$ \\
\hline \multirow[t]{6}{*}{ C. tribiliformis } & CMW13015 & AY529004 & ITS & CBS 115949 & Pinus mercusii & M.J. Wingfield & Indonesia \\
\hline & & AY528994 & BT1 & $"$ & $"$ & $"$ & $"$ \\
\hline & & AY529015 & TEF & $"$ & $"$ & $"$ & $"$ \\
\hline & CMW13013 & AY529003 & ITS & CBS 115866 & $"$ & M.J. Wingfield & Indonesia \\
\hline & & AY528993 & BT1 & $"$ & $"$ & $"$ & $"$ \\
\hline & & AY529014 & TEF & $"$ & $"$ & $"$ & $"$ \\
\hline \multirow[t]{3}{*}{ C. tsitsikammensis } & CMW14276 & EF408555 & ITS & CBS 121018 & Rapanea melanophloeos & G.N. Kamgan \& J. Roux & South Africa \\
\hline & & EF408569 & BT1 & $"$ & $"$ & $"$ & $"$ \\
\hline & & EF408576 & TEF & $"$ & $"$ & $"$ & $"$ \\
\hline \multirow[t]{6}{*}{ C. tyalla } & CMW28925 & HM071897 & ITS & CBS 127211 & E. pilularis & G.N. Kamgan & Australia \\
\hline & & HM071911 & BT1 & $"$ & $"$ & $"$ & $"$ \\
\hline & & HQ236450 & TEF & $"$ & $"$ & $"$ & $"$ \\
\hline & CMW28932 & HM071900 & ITS & CBS 128703 & E. dunnii & $"$ & $"$ \\
\hline & & HM071913 & BT1 & $"$ & $"$ & $"$ & $"$ \\
\hline & & HQ236452 & TEF & $"$ & $"$ & $"$ & $"$ \\
\hline \multirow[t]{3}{*}{ C. variospora } & CMW20935 & EF070421 & ITS & CBS 114715 & Quercus alba & J. Johnson & USA \\
\hline & & EF070437 & BT1 & $"$ & $"$ & $"$ & $"$ \\
\hline & & EF070409 & TEF & $"$ & $"$ & $"$ & $"$ \\
\hline \multirow[t]{3}{*}{ C. virescens } & CMW3276 & DQ061281 & ITS & NA & Quercus sp. & T. Hinds & USA \\
\hline & & AY528990 & BT1 & $"$ & $"$ & $"$ & $"$ \\
\hline & & AY529011 & TEF & $"$ & $"$ & $"$ & $"$ \\
\hline \multirow[t]{6}{*}{ C. zombamontana } & CMW15235 & EU245002 & ITS & CBS 122297 & Eucalyptus sp. & R.N. Heath \& J. Roux & Malawi \\
\hline & & EU244974 & BT1 & $"$ & $"$ & $"$ & $"$ \\
\hline & & EU244934 & TEF & $"$ & $"$ & $"$ & $"$ \\
\hline & CMW15236 & EU245000 & ITS & CBS 122296 & $"$ & $"$ & $"$ \\
\hline & & EU244972 & BT1 & $"$ & $"$ & $"$ & $"$ \\
\hline & & EU244932 & TEF & $"$ & $"$ & $"$ & $"$ \\
\hline
\end{tabular}


Table 5 Tree statistics for Maximum Parsimony analyses

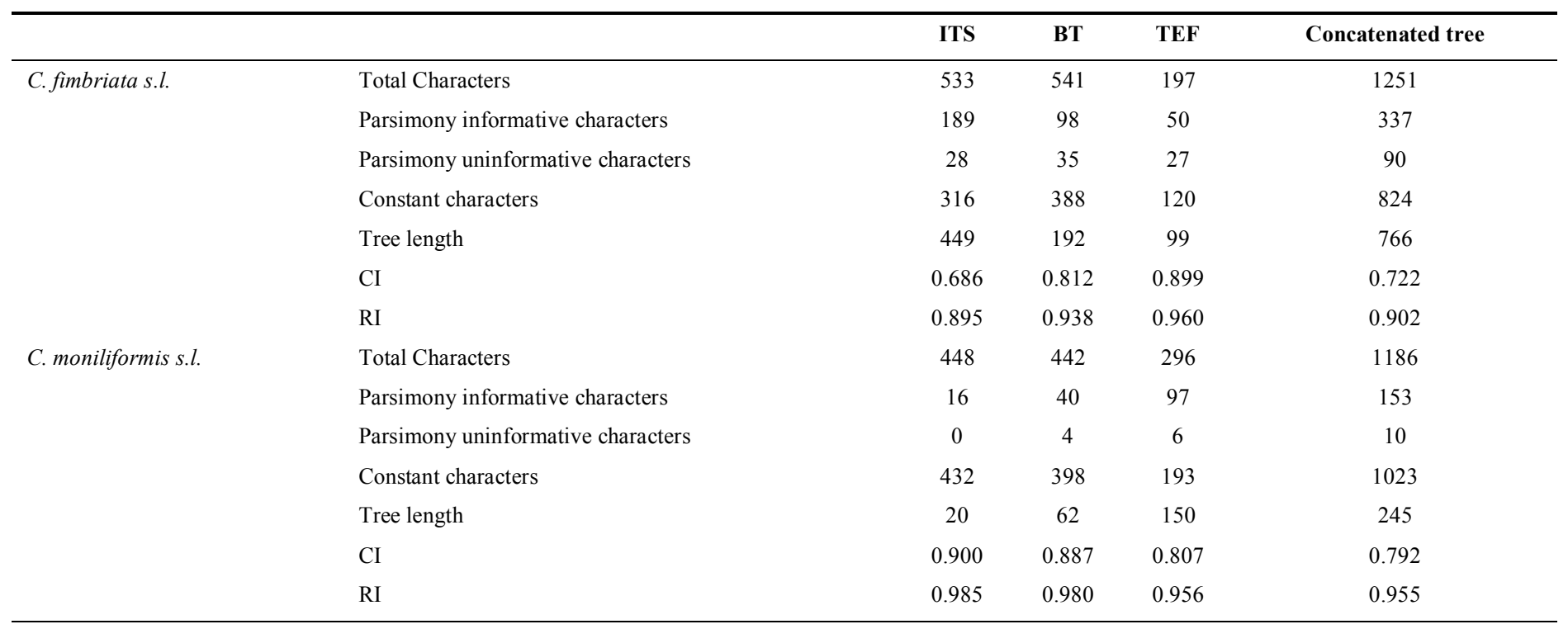

Table 6 Number of fixed base pairs across the ITS gene region showing differences between species in the C. pirilliformis s.l. clade of Ceratocystis

\begin{tabular}{|c|c|c|c|c|c|c|c|c|c|c|c|c|c|c|c|}
\hline \multirow[t]{2}{*}{ Isolates } & \multicolumn{15}{|c|}{ ITS } \\
\hline & 19 & 23 & 95 & 110 & 122 & 123 & 157 & 176 & 192 & 193 & 280 & 283 & 350 & 352 & 421 \\
\hline CMW6579-C. pirilliformis & . & . & - & . & . & . & . & $\mathbf{A}$ & - & - & . & . & . & . & - \\
\hline CMW29822-C. pirilliformis & . & . & - & $\cdot$ & $\cdot$ & · & . & - & - & . & . & . & $\cdot$ & $\cdot$ & $\cdot$ \\
\hline CMW27184-C. pirilliformis & . & . & - & . & · & - & . & . & . & . & . & . & · & . & $\cdot$ \\
\hline CMW27047-C. pirilliformis & . & . & - & . & - & · & · & - & . & - & $\mathbf{A}$ & . & . & . & . \\
\hline CMW23807-C. obpyriformis & . & $\mathbf{A}$ & • & G & · & · & . & . & . & . & . & $\mathbf{A}$ & . & · & - \\
\hline CMW23808-C. obpyriformis & . & $\mathbf{A}$ & . & G & . & . & . & . & . & . & . & $\mathbf{A}$ & . & . & - \\
\hline CMW23809-C. polyconidia & . & . & - & . & . & . & . & . & . & . & . & . & C & C & . \\
\hline CMW23818-C. polyconidia & . & . & - & . & . & . & . & . & . & . & . & . & C & C & . \\
\hline
\end{tabular}


Table 7 Number of fixed base pairs across the ITS gene region showing differences between species in the $C$. pirilliformis s.l. clade of Ceratocystis

\begin{tabular}{|c|c|c|c|c|c|c|c|c|c|c|c|c|}
\hline Isolates & CMW6569 & CMW6579 & CMW29825 & CMW29822 & CMW27184 & CMW27047 & CMW15235 & CMW15236 & CMW23807 & CMW23808 & CMW23809 & CMW23818 \\
\hline CMW6569-C. pirilliformis & $\mathbf{0}$ & & & & & & & & & & & \\
\hline CMW6579-C. pirilliformis & 3 & $\mathbf{0}$ & & & & & & & & & & \\
\hline CMW29825-C. pirilliformis & 7 & 6 & $\mathbf{0}$ & & & & & & & & & \\
\hline CMW29822-C. pirilliformis & 1 & 2 & 6 & $\mathbf{0}$ & & & & & & & & \\
\hline CMW27184-C. pirilliformis & 1 & 2 & 6 & $\mathbf{0}$ & $\mathbf{0}$ & & & & & & & \\
\hline CMW27047-C. pirilliformis & 1 & 3 & 7 & 1 & 1 & $\mathbf{0}$ & & & & & & \\
\hline CMW15235-C. zombamontana & 8 & 7 & 1 & 7 & 7 & 8 & $\mathbf{0}$ & & & & & \\
\hline CMW15236-C. zombamontana & 8 & 7 & 1 & 7 & 7 & 8 & $\mathbf{0}$ & $\mathbf{0}$ & & & & \\
\hline CMW23807-C. obpyriformis & 4 & 5 & 9 & 5 & 5 & 6 & 10 & 10 & $\mathbf{0}$ & & & \\
\hline CMW23808-C. obpyriformis & 4 & 5 & 9 & 5 & 5 & 6 & 10 & 10 & $\mathbf{0}$ & $\mathbf{0}$ & & \\
\hline CMW23809-C. polyconidia & 3 & 4 & 8 & 2 & 2 & 3 & 9 & 9 & 7 & 7 & $\mathbf{0}$ & \\
\hline CMW23818-C.polyconidia & 3 & 4 & 8 & 2 & 2 & 3 & 9 & 9 & 7 & 7 & $\mathbf{0}$ & $\mathbf{0}$ \\
\hline
\end{tabular}

Table 8 Number of haplotypes and their frequencies amongst species in the $C$. pirilliformis s.l. clade of Ceratocystis

\begin{tabular}{ccll}
\hline Haplotype numbers & Frequencies & Isolate numbers & Haplotype designation \\
\hline 1 & 3 & CMW15235 & C. zombamontana \\
1 & 3 & CMW15236 & " \\
1 & 3 & CMW29825 & C. pirilliformis \\
2 & 2 & CMW29822 & $"$ \\
2 & 2 & CMW29184 & $"$ \\
3 & 1 & CMW27047 & $"$ \\
4 & 1 & CMW6569 & $"$ \\
5 & 1 & CMW6579 & C. obpyriformis \\
6 & 2 & CMW23807 & $"$ \\
6 & 2 & CMW23808 & C. polyconidia \\
7 & 2 & CMW23809 & \\
7 & 2 & CMW23818 &
\end{tabular}


Table 9 Summary of polymorphic nucleotides found within the BT1 gene region generated from phylogenetic analyses and showing differences between $C$. salinaria, $C$. decipiens and closest related taxa

\begin{tabular}{|c|c|c|c|c|c|c|c|c|c|c|c|c|c|c|c|c|c|c|}
\hline \multirow[t]{2}{*}{ Isolates } & \multicolumn{18}{|c|}{ BT1 } \\
\hline & 14 & 116 & 126 & 127 & 131 & 134 & 138 & 139 & 140 & 141 & 143 & 150 & 158 & 167 & 168 & 254 & 323 & 335 \\
\hline CMW17300-C. savannae & C & $\mathbf{T}$ & C & $\mathbf{T}$ & $\mathbf{T}$ & $\mathbf{C}$ & $\mathbf{A}$ & $\mathbf{T}$ & C & $\mathbf{A}$ & $\mathbf{A}$ & G & $\mathbf{C}$ & $\mathbf{T}$ & $\mathbf{C}$ & $\mathrm{C}$ & $\mathbf{T}$ & $\mathbf{T}$ \\
\hline CMW17297-C. savannae & . & . & . & . & . & . & . & . & . & . & . & . & . & . & . & . & . & . \\
\hline CMW30824-C. savannae & . & . & . & . & . & . & . & . & . & . & G & . & . & . & . & $\mathbf{T}$ & . & . \\
\hline CMW30846-C. savannae & . & . & . & . & . & . & . & . & . & . & . & . & . & . & . & . & . & . \\
\hline CMW30839-C. savannae & $\mathbf{T}$ & . & . & . & . & . & . & . & . & . & . & . & . & . & . & . & . & . \\
\hline CMW23803-C. oblonga & $\cdot$ & $\mathbf{C}$ & $\mathbf{T}$ & $\mathrm{C}$ & . & . & . & . & $\mathbf{T}$ & $\cdot$ & . & . & . & . & . & . & . & . \\
\hline CMW23802-C. oblonga & . & $\mathbf{C}$ & $\mathbf{T}$ & $\mathrm{C}$ & . & . & . & . & $\mathbf{T}$ & $\cdot$ & . & . & . & . & . & . & . & . \\
\hline CMW30845-C. oblonga & . & $\mathbf{C}$ & . & $\mathrm{C}$ & . & . & . & . & $\mathbf{T}$ & . & . & . & $\mathbf{T}$ & . & $\mathbf{A}$ & . & . & . \\
\hline CMW30835-C. oblonga & . & $\mathbf{C}$ & . & $\mathrm{C}$ & . & . & . & . & $\mathbf{T}$ & . & . & . & $\mathbf{T}$ & . & $\mathbf{A}$ & . & . & . \\
\hline CMW30698-C. oblonga & . & $\mathbf{C}$ & . & $\mathrm{C}$ & . & . & . & . & $\mathbf{T}$ & . & . & . & $\mathbf{T}$ & . & . & . & . & . \\
\hline CMW25918-C. decipiens & . & $\mathbf{C}$ & . & $\mathrm{C}$ & . & . & . & $\mathbf{C}$ & . & . & . & $\mathbf{A}$ & . & . & . & . & $\mathbf{C}$ & C \\
\hline CMW25914-C. decipiens & . & $\mathbf{C}$ & . & $\mathrm{C}$ & . & $\mathbf{A}$ & . & $\mathbf{C}$ & . & . & . & $\mathbf{A}$ & . & . & . & . & $\mathbf{C}$ & C \\
\hline CMW30701-C. decipiens & . & $\mathbf{C}$ & . & $\mathrm{C}$ & . & . & . & $\mathbf{C}$ & . & . & . & $\mathbf{A}$ & . & . & . & . & $\mathbf{C}$ & C \\
\hline CMW30855-C. decipiens & . & $\mathbf{C}$ & . & $\mathrm{C}$ & . & . & . & $\mathbf{C}$ & . & . & . & $\mathbf{A}$ & . & . & . & . & $\mathbf{C}$ & C \\
\hline CMW30830-C. decipiens & . & $\mathbf{C}$ & . & $\mathbf{C}$ & $\cdot$ & . & . & $\mathbf{C}$ & . & . & . & $\mathbf{A}$ & . & . & . & . & $\mathbf{C}$ & C \\
\hline CMW30704-C. salinaria & . & $\mathbf{C}$ & . & $\mathrm{C}$ & G & $\mathbf{T}$ & $\mathbf{G}$ & . & . & $\mathbf{G}$ & . & . & . & A & . & . & $\mathbf{C}$ & C \\
\hline CMW30703-C. salinaria & . & $\mathbf{C}$ & . & $\mathrm{C}$ & $\mathbf{G}$ & $\mathbf{T}$ & G & . & . & $\mathbf{G}$ & . & . & . & A & . & . & . & C \\
\hline CMW30702-C. salinaria & . & $\mathbf{C}$ & . & $\mathrm{C}$ & $\mathbf{G}$ & $\mathbf{T}$ & $\mathbf{G}$ & . & . & $\mathbf{G}$ & . & . & . & $\mathbf{A}$ & . & . & . & C \\
\hline CMW25911-C. salinaria & . & $\mathbf{C}$ & . & $\mathbf{C}$ & $\mathbf{G}$ & $\mathbf{T}$ & G & . & . & $\mathbf{G}$ & . & . & . & $\mathbf{A}$ & . & . & . & C \\
\hline
\end{tabular}


Table 10 Summary of polymorphic nucleotides found within the TEF gene region generated from phylogenetic analyses and showing differences between $C$. salinaria, $C$. decipiens and closest related taxa

\begin{tabular}{|c|c|c|c|c|c|c|c|c|c|c|c|c|c|c|c|c|c|c|c|c|c|c|c|c|c|c|c|c|c|c|c|}
\hline Isolates & & & & & & & & & & & & & & & & & TEI & & & & & & & & & & & & & & \\
\hline & 4 & 6 & 9 & 10 & 16 & 18 & 29 & 32 & 34 & 35 & 36 & 46 & 50 & 55 & 61 & 65 & 71 & 75 & 83 & 123 & 130 & 139 & 168 & 186 & 233 & 256 & 258 & 259 & 262 & 275 & 284 \\
\hline CMW17300-C. savannae & C & $\mathbf{T}$ & A & $\mathbf{T}$ & C & - & G & $\mathbf{T}$ & $\mathbf{A}$ & $\mathbf{T}$ & G & G & G & $\mathbf{T}$ & $\mathbf{A}$ & G & C & $\mathbf{T}$ & $\mathbf{G}$ & C & C & $\mathbf{G}$ & $\mathbf{T}$ & $\mathbf{A}$ & G & $\mathbf{A}$ & $\mathbf{A}$ & G & $\mathbf{T}$ & $\mathbf{T}$ & A \\
\hline CMW17297-C. savannae & . & . & . & . & . & - & . & . & . & . & . & . & . & . & $\cdot$ & . & . & . & . & . & . & . & - & $\cdot$ & · & - & - & • & & & \\
\hline CMW30824-C. savannae & . & . & . & . & . & - & . & . & . & . & . & . & . & A & . & . & . & . & . & . & . & . & . & . & . & . & . & $\mathbf{A}$ & . & . & . \\
\hline CMW30846-C. savannae & . & . & $\cdot$ & . & . & - & : & . & : & $\cdot$ & . & $\cdot$ & $\cdot$ & $\cdot$ & $\cdot$ & $\cdot$ & $\cdot$ & $\cdot$ & i & . & $\cdot$ & - & - & - & - & . & - & & . & $\cdot$ & . \\
\hline $\begin{array}{l}\text { CMW30839-C. savannae } \\
\text { CMW23803-C. oblonga }\end{array}$ & $\dot{T}$ & $\dot{\mathrm{C}}$ & $\dot{G}$ & $\dot{\mathrm{C}}$ & $\dot{T}$ & 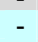 & : & $\dot{\mathbf{C}}$ & . & . & $\cdot$ & : & $\dot{0}$ & . & : & $\dot{.}$ & $\dot{\mathbf{T}}$ & . & A & : & - & - & : & : & & : & $\mathbf{T}$ & & & : & : \\
\hline CMW23802-C. oblonga & $\mathbf{T}$ & C & G & C & $\mathbf{T}$ & - & . & C & . & . & . & . & . & . & . & . & $\mathbf{T}$ & . & . & . & . & . & . & . & . & . & $\mathbf{T}$ & & . & . & . \\
\hline CMW30845-C. oblonga & . & . & . & . & . & - & . & . & . & . & . & . & . & . & . & . & . & . & . & . & . & . & . & . & • & 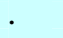 & . & 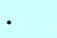 & . & . & . \\
\hline CMW30835-C. oblonga & . & . & . & . & . & - & . & . & . & . & . & . & . & . & . & . & . & . & $\mathbf{A}$ & . & . & . & . & . & & . & . & & . & & . \\
\hline CMW30698-C. oblonga & - & . & . & . & . & - & & . & & & - & . & & . & & & . & $\dot{x}$ & . & $\dot{\dot{c}}$ & & . & & . & & - & - & & & & . \\
\hline CMW25918-C. decipiens & . & . & . & . & . & - & C & . & G & $\mathbf{G}$ & - & A & A & . & G & A & . & C & . & G & $\mathbf{T}$ & A & $\mathbf{A}$ & . & C & - & - & & C & - & . \\
\hline CMW25914-C. decipiens & . & . & . & . & . & - & C & . & $\mathbf{G}$ & G & & A & A & . & G & A & . & C & . & G & $T$ & A & $\mathbf{A}$ & . & $\mathrm{C}$ & & . & . & C & & \\
\hline CMW30701-C. decipiens & . & . & & . & . & - & C & . & G & $\mathbf{G}$ & A & . & A & . & . & A & . & C & . & G & . & . & G & $\mathbf{G}$ & & $\mathbf{T}$ & . & & C & C & G \\
\hline CMW30855-C. decipiens & . & . & . & . & . & - & C & . & G & $\mathbf{G}$ & A & . & A & . & . & A & . & C & . & G & . & . & G & G & & $\mathbf{T}$ & . & & C & C & G \\
\hline CMW30830-C. decipiens & . & . & . & - & . & - & C & . & G & $\mathbf{G}$ & A & 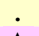 & A & . & . & A & . & C & . & G & & . & G & G & & $\mathbf{T}$ & & & C & $\mathrm{C}$ & G \\
\hline CMW30704-C. salinaria & ${ }^{\circ}$ & $\cdot$ & $\cdot$ & 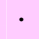 & . & $\mathbf{T}$ & C & . & G & $\mathbf{G}$ & . & A & A & . & . & $\mathbf{A}$ & . & C & . & $\mathbf{G}$ & $T$ & . & $\mathbf{A}$ & . & & . & $\mathbf{G}$ & & C & . & . \\
\hline CMW30703-C. salinaria & . & & & . & . & - & C & . & G & $\mathbf{G}$ & & A & A & . & . & A & . & C & . & G & $T$ & . & $\mathbf{A}$ & . & & - & G & & C & . & . \\
\hline CMW30702-C. salinaria & . & . & . & . & . & - & C & . & G & $\mathbf{G}$ & . & A & A & . & . & A & . & C & . & G & $\mathbf{T}$ & . & $\mathbf{A}$ & . & & . & G & & C & . & . \\
\hline CMW25911-C. salinaria & & & & & & - & C & & G & $\mathbf{G}$ & & A & A & & & A & & C & & G & $\mathbf{T}$ & & $\mathbf{A}$ & & & & G & & $\mathrm{C}$ & & \\
\hline
\end{tabular}




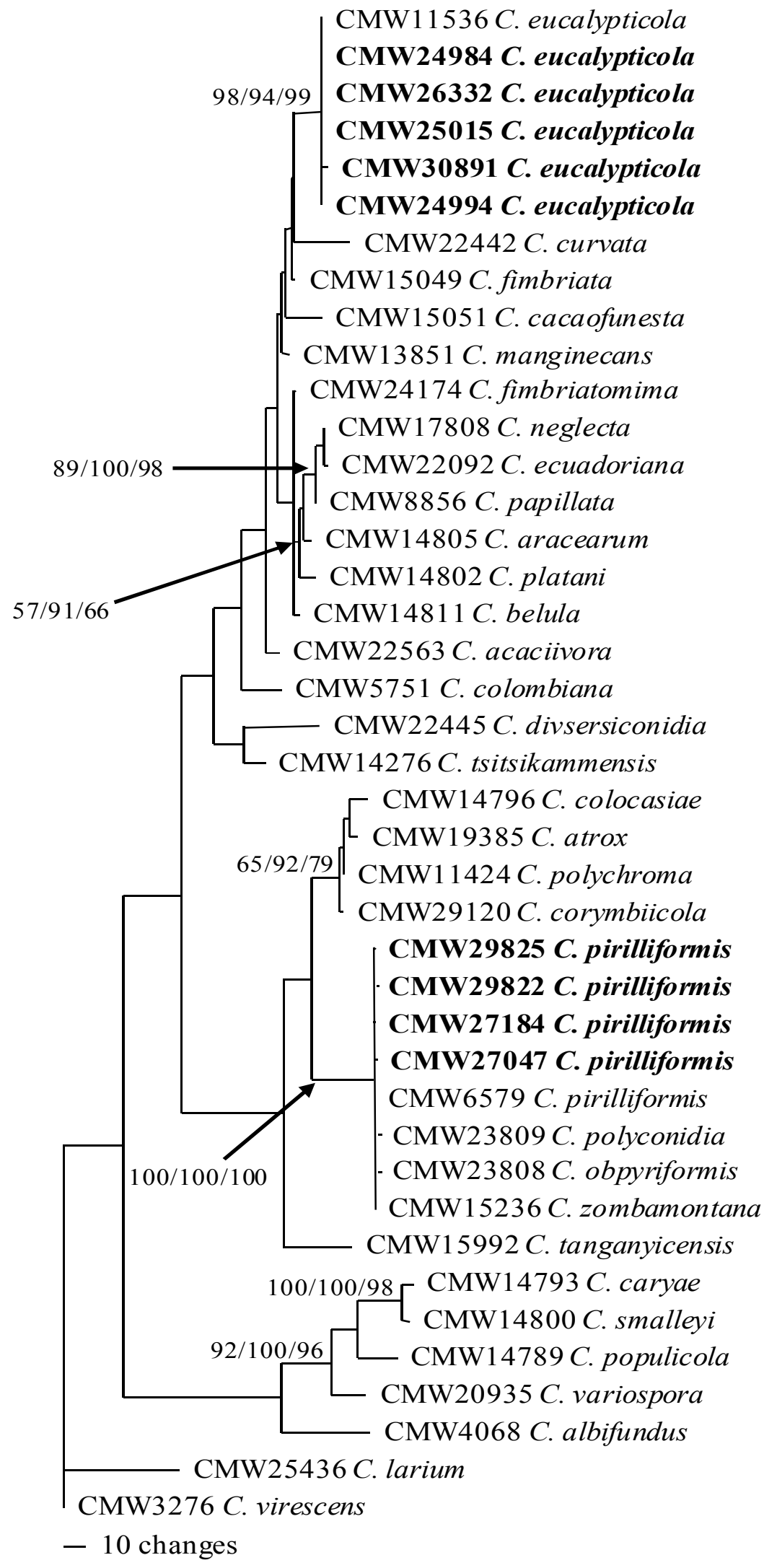

Fig. 1 Phylogenetic tree produced from a heuristic search of the ITS sequence data, showing the relationship between members of $C$. fimbriata s.l. Isolates sequenced in this study are in bold font type. C. virescens was used as out-group taxon. MP bootstrap values, Bayesian posterior probabilities and ML bootstrap values respectively are indicated at each relevant node 


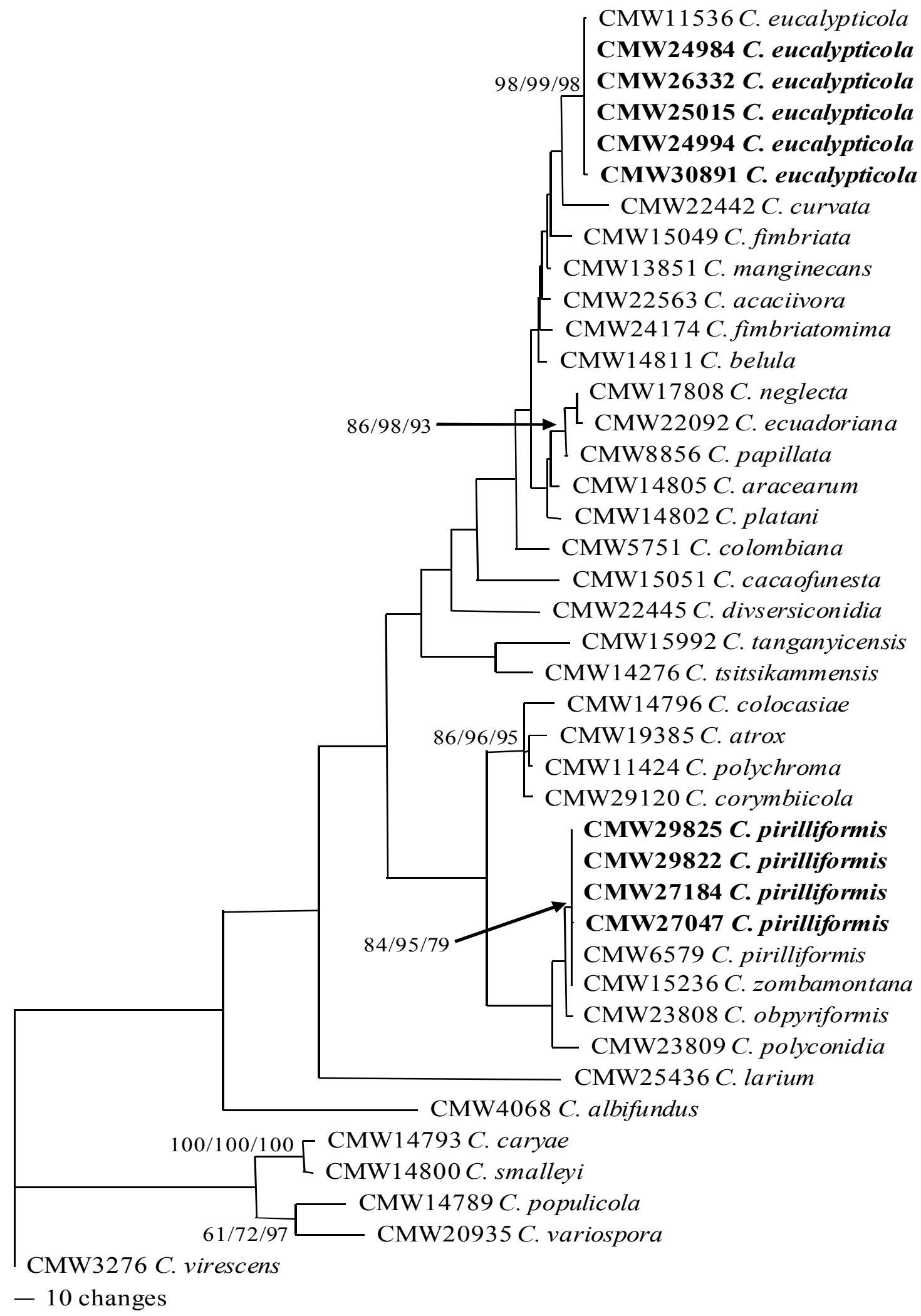

Fig. 2 Phylogenetic tree produced from a heuristic search of the combined ITS, BT1 and TEF sequence data, showing the relationship between members of $C$. fimbriata s.l. Isolates sequenced in this study are in bold font type. C. virescens was used as out-group taxon. MP bootstrap values, Bayesian posterior probabilities and ML bootstrap values respectively are indicated at each relevant node 


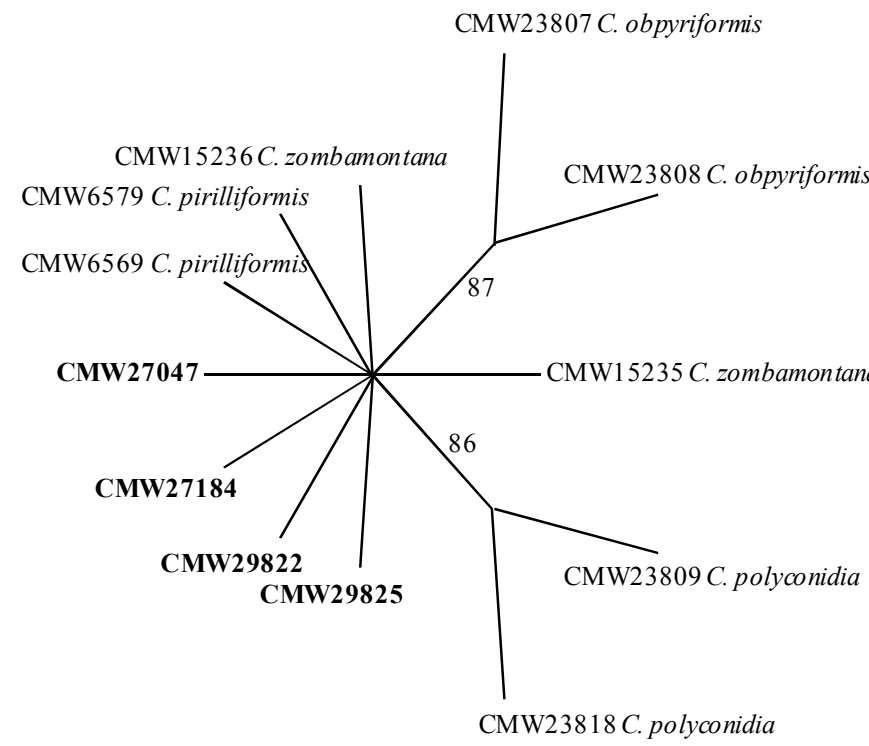

A

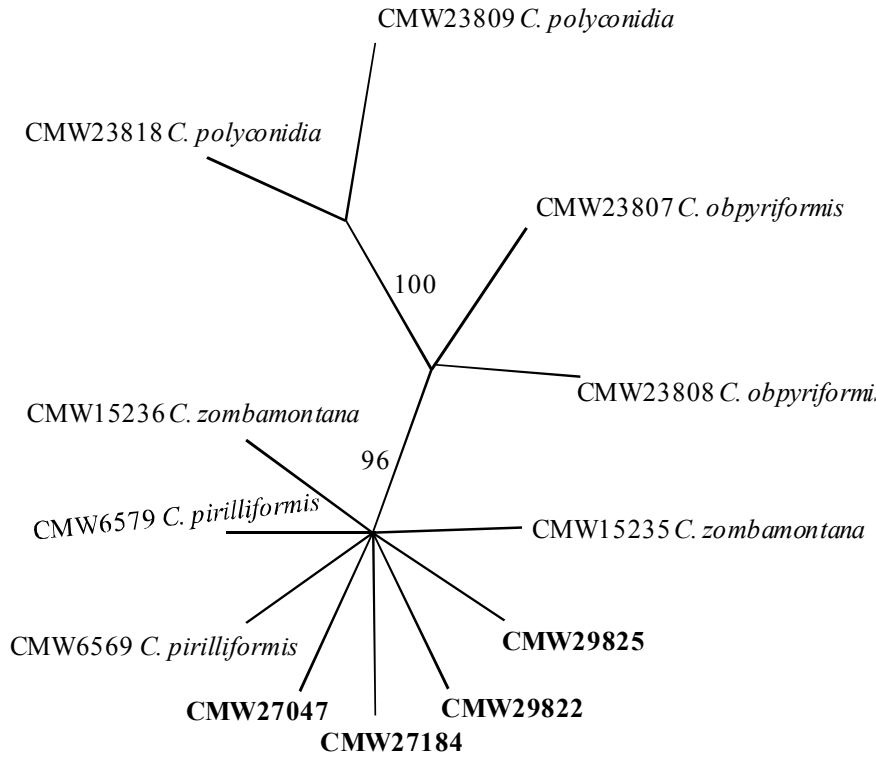

B



C

Fig. 3 Unrooted maximum parsimony tree produced from a heuristic search of the ITS (Fig. A) BT1 (Fig. B) and TEF (Fig. C) sequence data respectively, showing the relationship between species within the $C$. pirilliformis s.l. clade. All isolates sequenced are in bold type. Bootstrap values were derived from 1000 replicates and are indicated next to each clade 
South Africa_C.pirilliformis

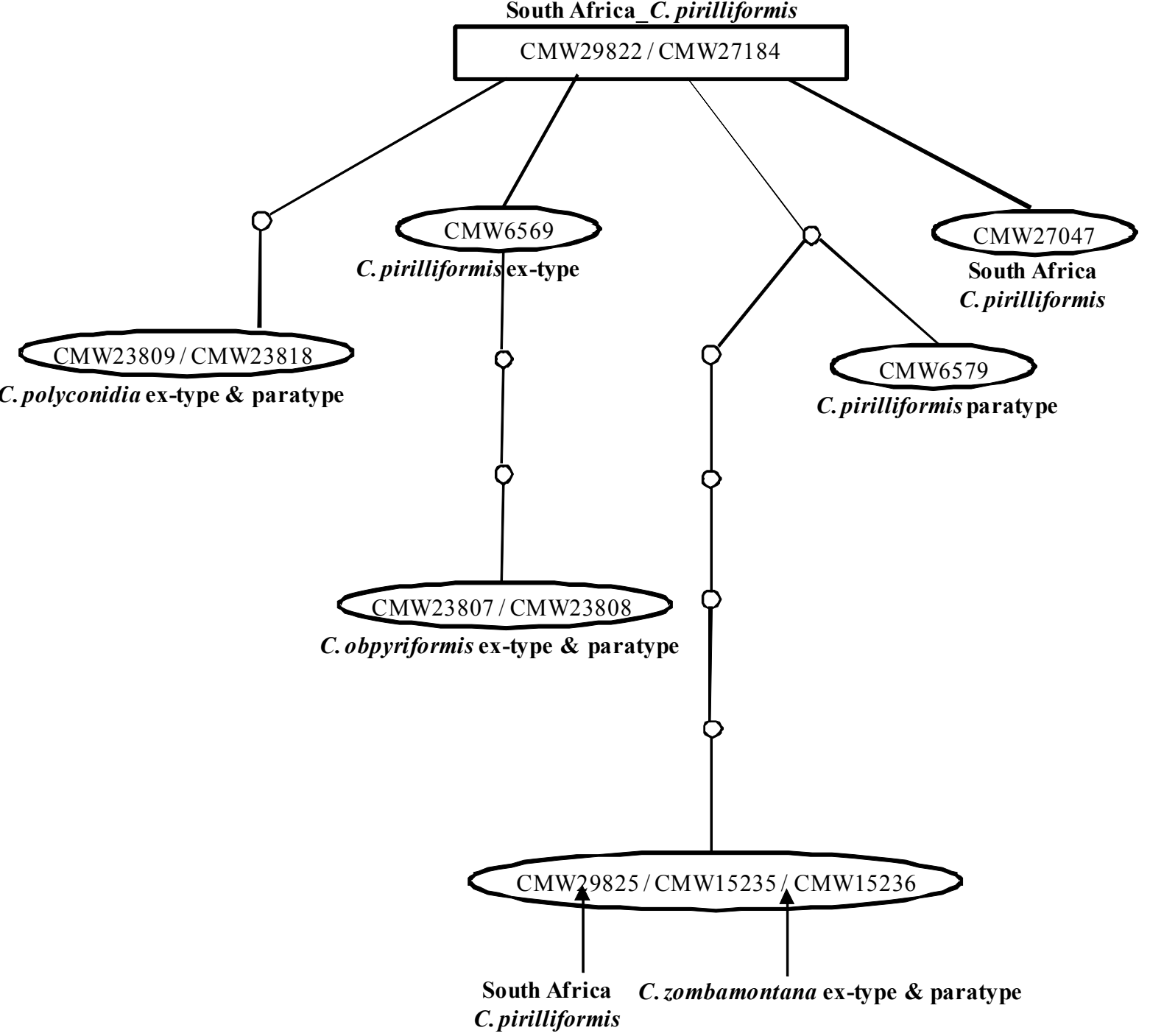

Fig. 4 Allele networks produced from ITS sequence data, showing the relationship between species in the C. pirilliformis s.1. clade comprising the type strains of $C$. pirilliformis (CMW6569, CMW6579), $C$. zombamontana (CMW15235, CMW15236), C. polyconidia (CMW23809, CMW23818), C. obpyriformis (CMW23807, CMW23808) and other isolates collected from South Africa (CMW29822, CMW27184, CMW27047, CMW29825) and identified as C. pirilliformis in this study. All four species are interconnected within the network, indicating that they originated from the same ancestral gene pool. However, C. polyconidia and C. obpyriformis each form single haplotypes distantly related from the other species 


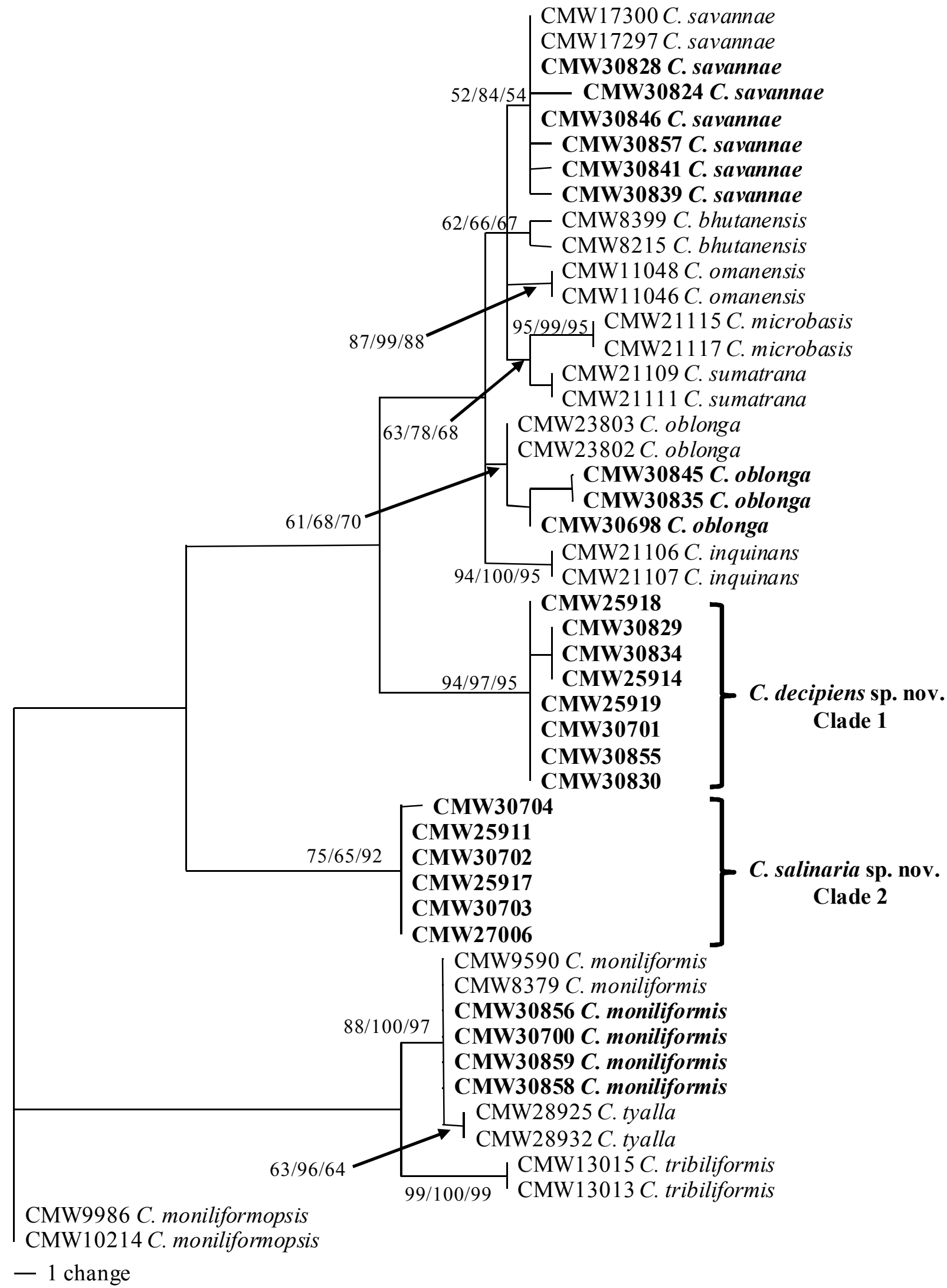

Fig. 5 Phylogenetic tree produced from a heuristic search of the BT1 sequence data, showing the relationship between members of $C$. moniliformis s.l. Isolates sequenced in this study are in bold font type. C. moniliformopsis was used as out-group taxon. MP bootstrap values, Bayesian posterior probabilities and ML bootstrap values respectively are indicated at each relevant node 


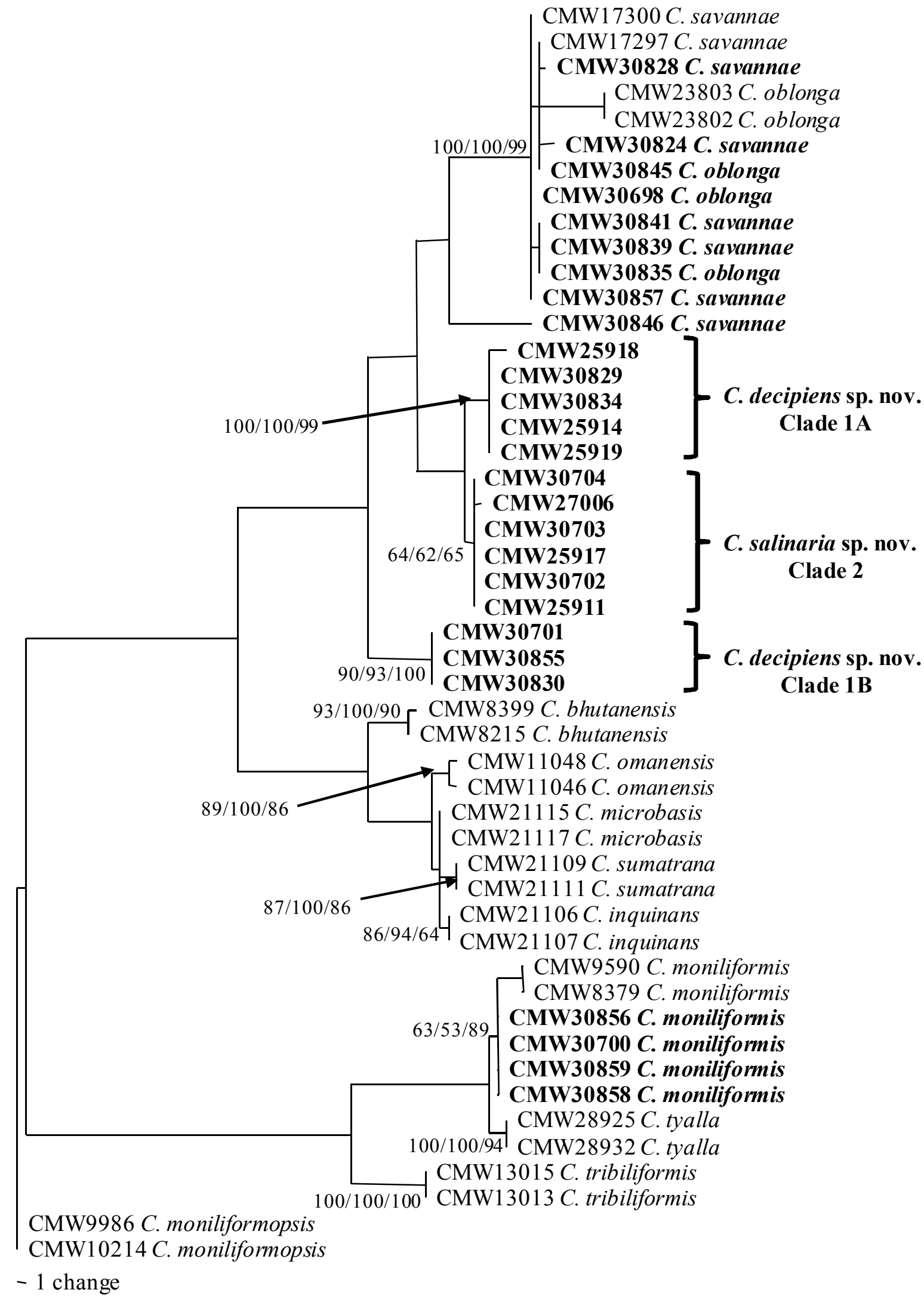

Fig. 6 Phylogenetic tree produced from a heuristic search of the TEF sequence data, showing the relationship between members of $C$. moniliformis s.l. Isolates sequenced in this study are in bold font type. C. moniliformopsis was used as out-group taxon. MP bootstrap values, Bayesian posterior probabilities and ML bootstrap values respectively are indicated at each relevant node 


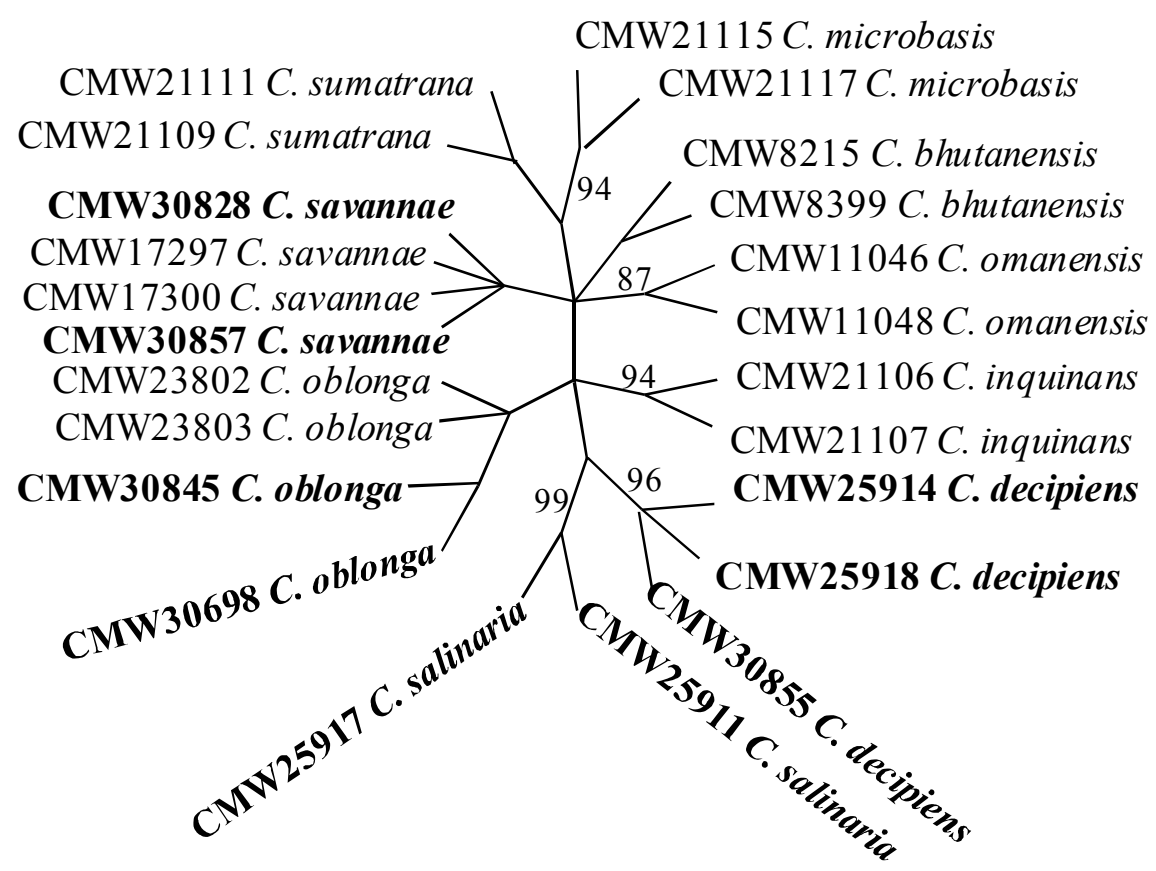

Fig. 7 Unrooted maximum parsimony tree produced from a heuristic search of the BT1 sequence data, showing the relationship between members of $C$. salinaria sp. nov., $C$. decipiens sp. nov. from Eucalyptus trees in South Africa and their most closely related neighbor in the C. moniliformis s.l. species complex 


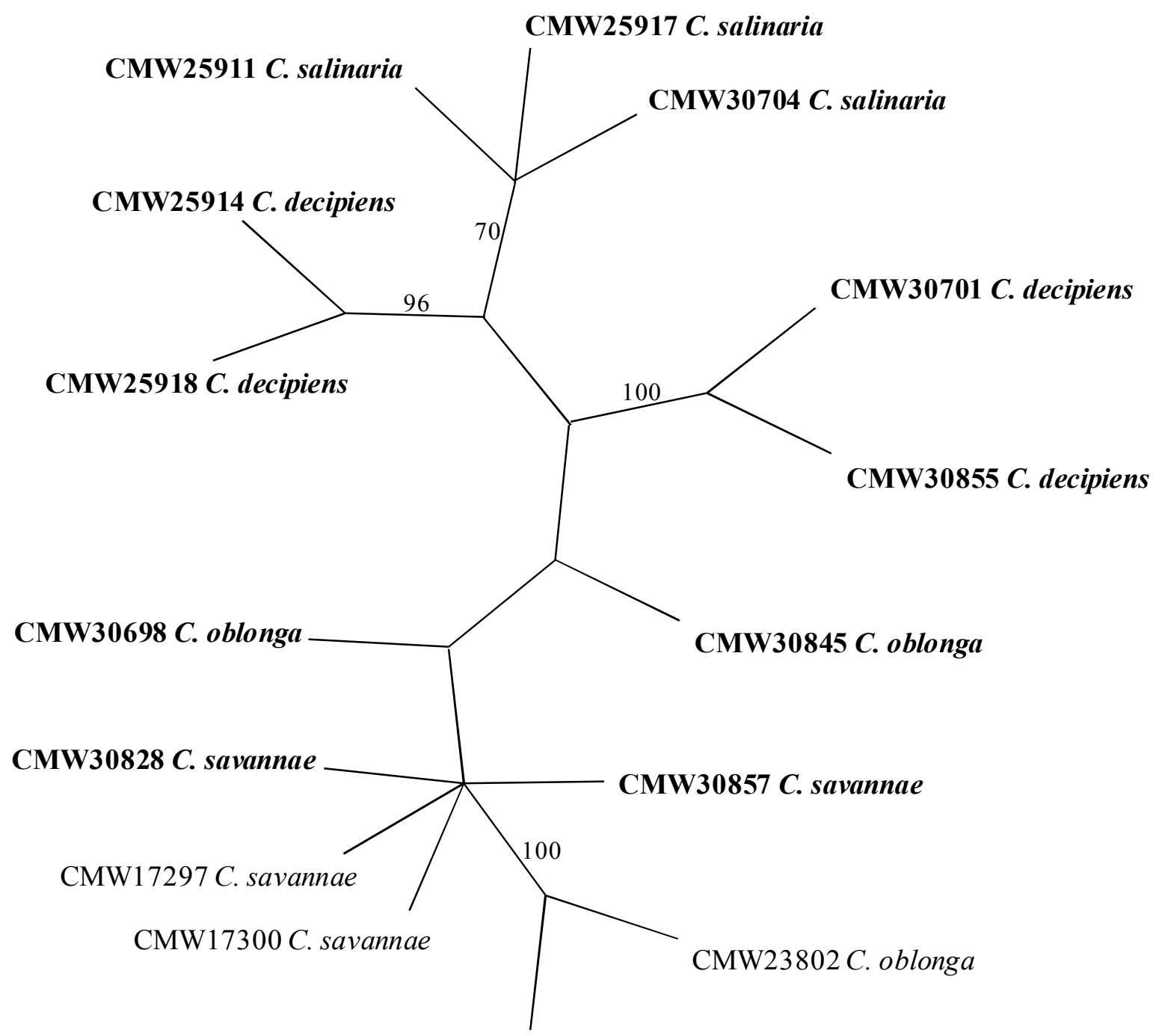

CMW23803 C. oblonga

Fig. 8 Unrooted maximum parsimony tree produced from a heuristic search of the TEF sequence data, showing the relationship between members of $C$. salinaria sp. nov., $C$. decipiens sp. nov. from Eucalyptus trees in South Africa and their most closely related neighbor in the C. moniliformis s.l. species complex 




Fig. 9 Phylogenetic tree produced from a heuristic search of the combined ITS, BT1 and TEF sequence data, showing the relationship between members of $C$. moniliformis s.l. Isolates sequenced in this study are in bold font type. C. moniliformopsis was used as out-group taxon. MP bootstrap values, Bayesian posterior probabilities and ML bootstrap values respectively are indicated at each relevant node 


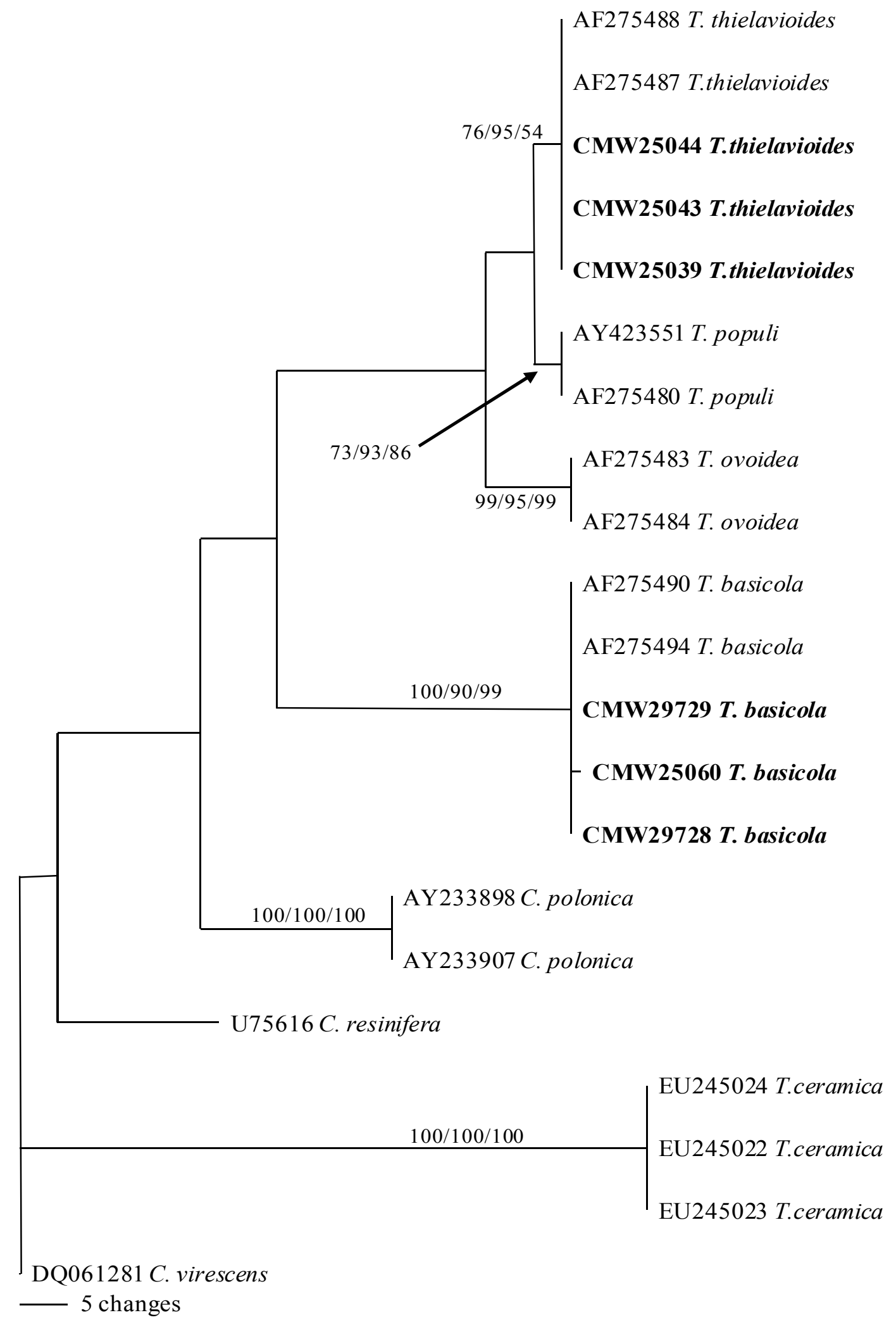

Fig. 10 Phylogenetic tree produced from a heuristic search of the ITS sequence data, showing the phylogenetic identity of Thielaviopsis strains collected in South Africa amongt other known Thielaviopsis spp. Isolates sequenced in this study are in bold font type. C. virescens was used as out-group taxon. MP bootstrap values are indicated at each relevant node 




Fig. 11 Morphological characteristics of Ceratocystis salinaria sp. nov. A) Globose ascomatal base (scale bar $=50 \mu \mathrm{m}), \mathrm{B})$ Hat-shaped ascospores $($ scale bar $=10 \mu \mathrm{m}), \mathrm{C})$ Divergent ostiolar hyphae (scale bar = $100 \mu \mathrm{m}$ ), D) Ascomatal base with conical spines (scale bar $=100 \mu \mathrm{m}$ ), E) Phialidic conidiogenous cell with emerging conidia (scale bar $=10 \mu \mathrm{m}$ ), F) Bacilliform shaped conidia (scale bar $=10 \mu \mathrm{m}), \mathrm{G})$ Oblong shaped conidia $($ scale bar $=10 \mu \mathrm{m})$ 


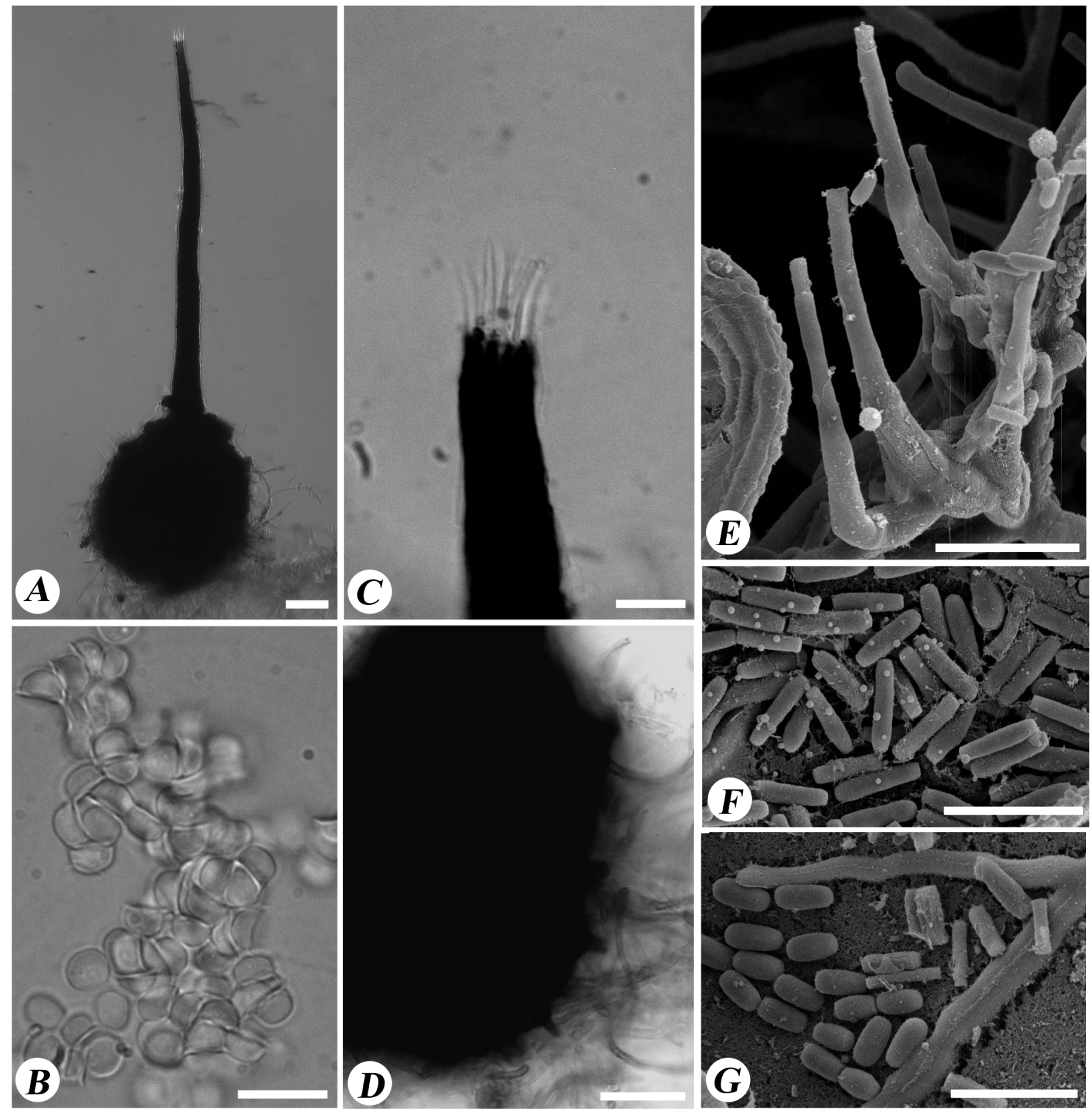

Fig. 12 Morphological characteristics of Ceratocystis decipiens sp. nov. A) Globose ascomatal base $($ scale bar $=50 \mu \mathrm{m}), \mathrm{B})$ Hat-shaped ascospores (scale bar $=10 \mu \mathrm{m}), \mathrm{C})$ Divergent ostiolar hyphae (scale bar $=10 \mu \mathrm{m})$, D) Ascomatal base with conical spines (scale bar $=100 \mu \mathrm{m})$, E) Phialidic conidiogenous cell with emerging conidia (scale bar $=10 \mu \mathrm{m}), \mathrm{F})$ Bacilliform shaped conidia (scale bar $=10 \mu \mathrm{m}), \mathrm{G})$ Oblong shaped conidia (scale bar $=10 \mu \mathrm{m})$ 


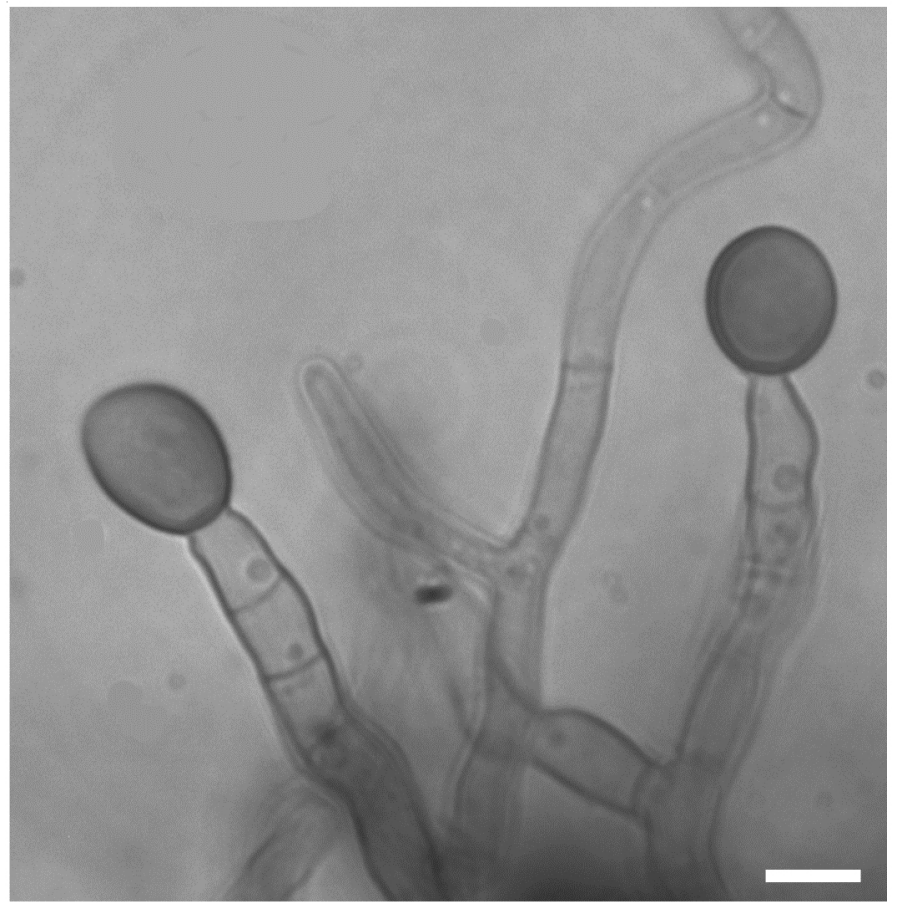

Fig. 13 Morphological characteristics of chlamydospores of C. zombamontana from isolate CMW15235 $($ scale bar $=5 \mu \mathrm{m})$


C. oblonga

C. decipiens

C. salinaria

T. thielavioides

C. pirilliformis

T. basicola

C. eucalypticola

C. moniliformis

C. savannate

Fig. 14 Map of South Africa showing the current geographic distribution of Ceratocystis spp. and Thielaviopsis spp. identified in this study from Eucalyptus spp. and insects in the country 